Check for updates

Cite this: Chem. Sci., 2019, 10, 5405

๑ All publication charges for this article have been paid for by the Royal Society of Chemistry

Received 15th February 2019

Accepted 20th April 2019

DOI: $10.1039 / c 9 s c 00793 h$

rsc.li/chemical-science

\section{Tuning the $\pi$-bridge of quadrupolar triarylborane chromophores for one- and two-photon excited fluorescence imaging of lysosomes in live cellst:}

\author{
Stefanie Griesbeck, (DD a Evripidis Michail, ${ }^{b}$ Chenguang Wang, ${ }^{c}$ Hiroaki Ogasawara, (D) ${ }^{c}$ \\ Sabine Lorenzen, ${ }^{a}$ Lukas Gerstner, ${ }^{a}$ Theresa Zang, ${ }^{a}$ Jörn Nitsch, (DD ${ }^{a}$ Yoshikatsu Sato, ${ }^{c}$ \\ Rüdiger Bertermann, ${ }^{a}$ Masayasu Taki, (D) C Christoph Lambert, (D) *b \\ Shigehiro Yamaguchi (D) *c and Todd B. Marder (D) *a
}

\begin{abstract}
A series of tetracationic quadrupolar chromophores containing three-coordinate boron $\pi$-acceptors linked by different $\pi$-bridges, namely 4,4'-biphenyl, 2,7-pyrene, 2,7-fluorene, 3,6-carbazole and 5,5'-di(thien-2yl)-3,6-diketopyrrolopyrrole, were synthesized. While their neutral precursors 1-5 displayed highly solvatochromic fluorescence, the water-soluble tetracationic target molecules $1 \mathrm{M}-5 \mathrm{M}$, did not, but their emission colour could be tuned from blue to pink by changing the $\pi$-bridge. Compound $5 \mathrm{M}$, containing the diketopyrrolopyrrole bridge, exhibits the most red-shifted absorption and emission maxima and the largest two-photon absorption cross-section (4560 GM at $740 \mathrm{~nm}$ in MeCN). Confocal laser scanning fluorescence microscopy studies in live cells confirm localization of the dye at the lysosome. Moreover, the low cytotoxicity, and high photostability of $5 \mathrm{M}$ combined with two-photon excited fluorescence imaging studies demonstrate its excellent potential for lysosomal imaging in live cells.
\end{abstract}

\section{Introduction}

The synthesis and applications of triarylboranes have increased tremendously in the last few decades. ${ }^{1-9}$ In order for the threecoordinate boron moiety to function as a strong $\pi$-electron acceptor (A) due to its vacant $\mathrm{p}_{z}$-orbital, the trigonal-planar geometry of the boron atom must be maintained, as its strong Lewis acidity can otherwise lead to binding of Lewis bases and/ or hydrolytic decomposition. This can be accomplished by the use of sterically demanding substituents, such as mesityl (Mes) or 2,4,6- $\left(\mathrm{CF}_{3}\right)_{3} \mathrm{C}_{6} \mathrm{H}_{2}\left({ }^{\mathrm{F}} \mathrm{Mes}\right),{ }^{\mathbf{1 0 , 1 1}}$ or by physical constraint, via incorporation in a rigid, planar structure. ${ }^{12}$ While the latter strategy prevents the formation of a four-coordinate boron species by inhibiting structural deformation, the former builds a propeller-like structure around the empty $\mathrm{p}_{z}$-orbital and obstructs the attack of nucleophiles, such as water, via the formation of a protective cage. Only small anions, such as fluoride and cyanide, can overcome the steric bulk and bind to

${ }^{a}$ Institut für Anorganische Chemie, and Institute for Sustainable Chemistry \& Catalysis with Boron, Julius-Maximilians-Universität Würzburg, 97074 Würzburg, Germany. E-mail: todd.marder@uni-wuerzburg.de

${ }^{b}$ Institut für Organische Chemie, Julius-Maximilians-Universität Würzburg, 97074 Würzburg, Germany. E-mail: christoph.lambert@uni-wuerzburg.de

'Institute of Transformative Bio-Molecules, Nagoya University, Nagoya, Japan. E-mail: yamaguchi@chem.nagoya-u.ac.jp

$\dagger$ Dedicated to Dr Jean-François Halet on the occasion of his $60^{\text {th }}$ birthday.

\$ Electronic supplementary information (ESI) available. See DOI: $10.1039 / \mathrm{c} 9 \mathrm{sc} 00793 \mathrm{~h}$ the free $\mathrm{p}_{z}$-orbital at the boron. ${ }^{13-15}$ For this reason, triarylborane acceptors are often used as selective $\mathrm{F}^{-}$and $\mathrm{CN}^{-}$ sensors. ${ }^{16-18}$ Three-coordinate boron species are also applied as emitting/electron transporting materials ${ }^{19-31}$ in organic light emitting diodes ${ }^{32}$ and redox-active materials. ${ }^{33-37}$ Furthermore, the electron deficiency of $\mathrm{BAr}_{3}$ acceptor units make them especially useful in intramolecular charge transfer compounds, when conjugated to a $\pi$-donor (D) moiety. ${ }^{38-46}$ As excitation induced charge transfer properties increase the two-photon absorption (TPA) probability, triarylborane acceptors have great potential for use in TPA and for two-photon excited fluorescence (TPEF). ${ }^{47,48}$

TPA is the simultaneous absorption of two photons via a virtual state, which is proportional to the square of the light intensity, whereas one-photon absorption is a linear process obeying Beer's Law. ${ }^{49-53}$ For this reason, two-photon absorption enables excitation of molecules within a very small volume ( femto liter) at the focus of a laser beam, which is useful for many applications. There is thus a strong demand for efficient two-photon absorption dyes for microfabrication, ${ }^{54-57}$ threedimensional data-storage, ${ }^{58-60}$ optical power limiting, ${ }^{61-63}$ laser up-conversion, ${ }^{64,65}$ photodynamic therapy ${ }^{66,67}$ and biological imaging. ${ }^{47,68-70}$ Especially for the latter application, relatively few small organic molecules have been studied, as they need to be highly specific for their biological target, highly photostable, water-stable and at least somewhat water-soluble to stain cells and tissues. In addition, the two-photon brightness $\left(\sigma_{2} \Phi_{\mathrm{f}}\right)$, where $\sigma_{2}$ is the two-photon absorption cross-section 
(comparable to an extinction coefficient) in GM and $\Phi_{\mathrm{f}}$ is the fluorescence quantum yield, should be at least $50 \mathrm{GM}$ to observe bright two-photon microscope images. ${ }^{47}$ Such probes have been applied as sensors of biomolecules (e.g. ions, reactive oxygen species (ROS), reactive sulphur species (RSS) and reactive nitrogen species (RNS)) and changes inside cells ( $\mathrm{pH}$, viscosity and polarity). ${ }^{71,72}$ However, two-photon dyes for monitoring and visualizing mitochondria and lysosomes are still limited.

Lysosomes are acidic ( $\mathrm{pH} 4.5-5.0)$ organelles in eukaryotic cells and are responsible for intracellular digestion degradation, secretion, plasma membrane repair, cell signalling, energy metabolism and endocrine regulation. ${ }^{73,74}$ Lysosomes are filled with more than 60 enzymes, the synthesis of which is controlled by nuclear genes. Mutations of these genes lead to lysosomal storage diseases, such as neurodegenerative disorders, e.g. Parkinson's disease and Alzheimer's disease, cardiovascular diseases and cancer. ${ }^{75}$ As they are acidic organelles, usually organic bases, such as morpholine, pyridine and dimethylamino groups, lead to accumulation in lysosomes. These terminal groups are typically attached to common dyes, such as naphthalene,$^{76-79}$ 1,8-naphthalimide ${ }^{80-88}$ indole ${ }^{89}$ coumarin, ${ }^{90}$ chromene $^{91}$ and fluorenone. ${ }^{92}$ Most of them are lysosome trackers, ${ }^{76,77,85,91,92}$ while others can sense $\mathrm{Zn}^{2+},{ }^{81} \mathrm{HClO},{ }^{79,82}$ $\mathrm{H}_{2} \mathrm{~S}^{86,89}$ thiols, ${ }^{83} \mathrm{NO},{ }^{80} \beta$-galactosidase, ${ }^{88} \mathrm{pH}^{78,84,87}$ or polarity ${ }^{90}$ within the lysosome. While all of the above-mentioned dyes are dipolar, quadrupolar chromophores for two-photon imaging of lysosomes are rare. It should be noted that efficient two-photon absorbing dyes bear the common structural motifs of dipolar, push-pull systems (D-A), quadrupolar $(\mathrm{D}-\pi-\mathrm{D}, \mathrm{A}-\pi-\mathrm{A})$ or octupolar systems $\left(\mathrm{DA}_{3}, \mathrm{AD}_{3}\right)$, with the latter two being often more efficient than dipoles. ${ }^{49,53}$ While the TPA properties of many quadrupoles have been studied, only a handful of those are used for imaging, especially of the lysosome. All eight such compounds which are, to our knowledge, the only ones, are depicted in Scheme 1.

In 2010, Belfield and co-workers reported ${ }^{93}$ the first quadrupolar TPEF imaging agent for lysosomes (A) which exhibited a very high two-photon brightness of $431 \mathrm{GM}$ in toluene. The dye localized in the lysosome, was found to be non-toxic and photostable. One year later, the same group reported three other compounds, B1, B2 and C, with $\sigma_{2} \Phi_{\mathrm{f}}$ of 1444, 1887 and 788 $\mathrm{GM}$, respectively, in cyclohexane. ${ }^{94,95}$ In the more polar solvent THF, the two-photon brightness of $\mathbf{B 1}$ decreased to $1 / 3$ and for compound $\mathbf{C}, \sigma_{2} \Phi_{\mathrm{f}}$ decreased to $1 / 9$ of its original value in a " 5 wt\% aqueous DMSO" solution. The brightness is usually much smaller in aqueous solution, due to the reduced quantum yield. Nevertheless, the three compounds show remarkably large values, due to their large conjugation lengths, but have relatively high molecular weights. Furthermore, these compounds are not water-soluble and must be premixed with Pluronic F-127, which is a block copolymer based on ethylene oxide and propylene oxide that is used for drug delivery. It encapsulates the chromophores upon formation of micelles facilitating dye up-take by the cells. In 2015, Cho's group reported the water-soluble dye $\mathbf{D} .^{96}$ Due to its negligible fluorescence in water, they measured its TPEF properties in a dioxanewater mixture and reported a brightness of $116 \mathrm{GM}$. The fluorenone dye $\mathbf{E}$ does not show bright fluorescence in water $\left(\Phi_{\mathrm{f}}=\right.$ $0.07)$; thus, its TPEF properties were measured in toluene $\left(\sigma_{2} \Phi_{\mathrm{f}}\right.$ $=150 \mathrm{GM}) .{ }^{97}$ The small size of the molecule might be the reason for its more modest two-photon brightness. Compounds $\mathbf{F}$ and $\mathbf{G}$ are two $\mathrm{pH}$-sensitive dyes for lysosome imaging. ${ }^{98}$ The

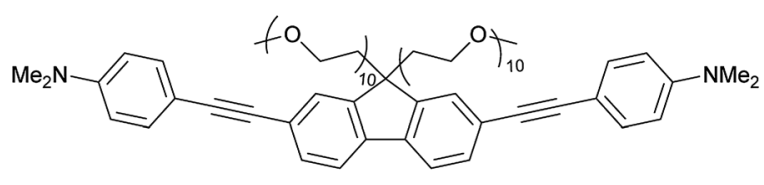

A

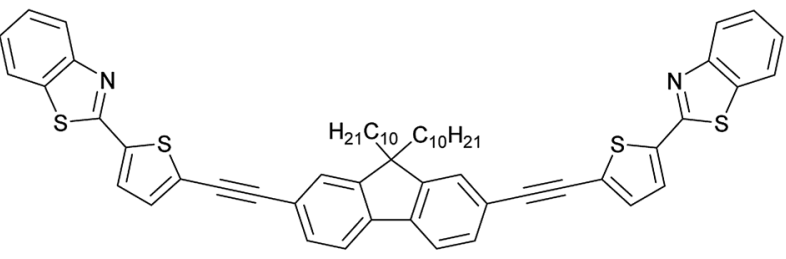

C

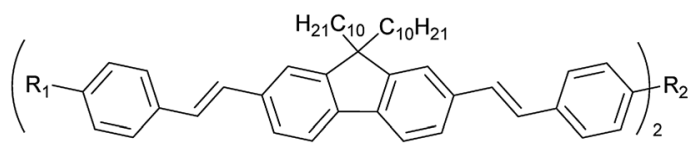

1: $R_{1}=N P h_{2} R_{2}=-\stackrel{O}{\prod_{O}}$

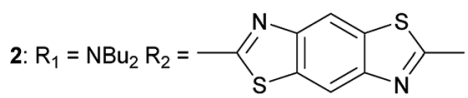

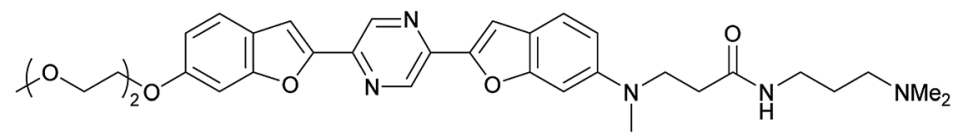

D
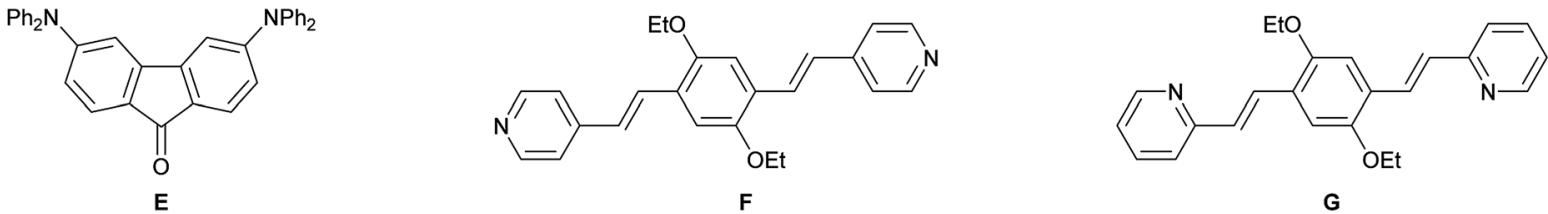

Scheme 1 Previously reported quadrupolar chromophores for two-photon excited fluorescence (TPEF) imaging of lysosomes. ${ }^{93-98}$ 
pyridine moiety acts as a ratiometric sensor for $\mathrm{pH}$ changes, as the protonation of the pyridine enhances intramolecular charge transfer. The two-photon cross-section increases, while the quantum yield drops at lower $\mathrm{pH}$ values. Therefore, the twophoton brightness maxima occur at $\mathrm{pH} 7$ for $\mathbf{F}$ (130 GM) and at $\mathrm{pH} 3$ for $\mathbf{G}$ (99 GM). Unfortunately, the selectivity of the dyes in the lysosome is less than excellent, as co-localization experiments showed an overlap with LysoTracker ${ }^{\mathrm{TM}}$ at lower $\mathrm{pH}$, but also distribution in the cytosol at neutral $\mathrm{pH}$.

As we have shown ${ }^{40,99-102}$ that quadrupolar compounds $(\mathrm{A}-\pi-$ A), with three-coordinate boron moieties as acceptors, exhibit large TPA cross-sections, we wished to apply them for imaging, but only a few water-soluble triarylboranes were known. Gabbaï and co-workers used trimethylammonio groups at the parapositions of triarylboranes to achieve water-solubility for sensing of cyanide in aqueous solution. ${ }^{\mathbf{1 0 3}}$ They and other groups also introduced cationic phosphonio substituents onto triarylboranes for further anion sensing studies. ${ }^{\mathbf{1 0 4 - 1 0 6}}$ Yang and co-workers were the first to report water-soluble threecoordinate boron compounds for imaging purposes. They substituted a triarylborane with polyethylene glycol chains for ATP sensing in the cytoplasm and cell membrane. ${ }^{107}$ Furthermore, they could sense $\mathrm{H}_{2} \mathrm{~S}$ with a $\mathrm{Cu}^{\mathrm{II}}$-cyclen-substituted triarylborane. ${ }^{108}$ They reported cell-membrane permeability and a preferential distribution at mitochondria, ${ }^{\mathbf{1 0 8}}$ while the same compound, without $\mathrm{Cu}^{\text {II }}$ binding, was used one year later to stain nucleoli and cytoplasm. ${ }^{109}$ However, a two-photon brightness of only $30 \mathrm{GM}$ in DMSO was measured for this compound. Two other triarylboranes with piperazine in the para-position were recently reported. They are water-soluble to some degree and were found to stain nucleoli as well as the nuclear membrane, nuclear matrix, nuclear pore and the cytoplasm, while binding to RNA. ${ }^{\mathbf{1 1 0}}$ Further three-coordinate boron containing dyes were used for imaging, although they were not water-soluble. ${ }^{\mathbf{1 1 1 - 1 1 5}}$ By loading them into nanogels, they became cell membrane permeable, stained the cytoplasm and could be applied as temperature, viscosity, $\mathrm{pH}, \mathrm{H}_{2} \mathrm{O}_{2}$ and biothiol sensors. ${ }^{\text {111-115 }}$ Another intracellular "turn-on"-sensor for thiophenol, based on a triarylborane moiety, was very recently published by Thilagar and co-workers. ${ }^{116}$ In 2016, our group reported the only water-soluble quadrupolar three-coordinate boron compound for imaging (2TM), which exhibited a very reasonable two-photon brightness of $285 \mathrm{GM}$ in MeCN (Scheme 2). ${ }^{117}$

With our very promising initial results with 2TM, we thus decided to optimize our imaging dye. Tuning the emission colour, enhancing the quantum yield, TPA cross-section and photostability, maintaining low cyto-toxicity, determining co-<smiles>Cc1cc(N(C)C(C)(C)C)cc(C)c1B(c1c(C)cc(N(C)C(C)(C)C)cc1C)c1c(C)cc(N(C)C(C)(C)C)cc1C</smiles>

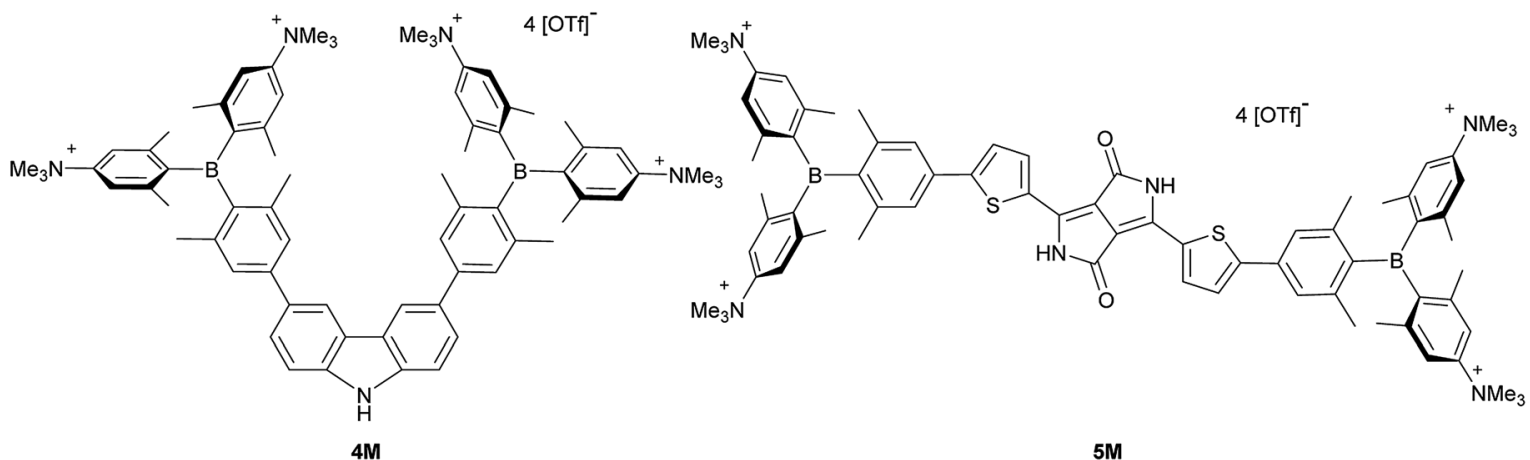

Scheme 2 Previously reported quadrupolar chromophore for TPEF imaging 2TM and quadrupolar target molecules $1 \mathrm{M}-5 \mathrm{M}$ for cell imaging. 
localization as well as examining the cellular uptake pathway were our main goals. For this purpose, we designed the new dyes 1M-5M shown in Scheme 2, all of which contain trimethylammonio groups for water-solubility. ${ }^{103}$ Due to the inductive withdrawing character of the ammonium cations, these triarylborane moieties are much stronger acceptors than the normally used aryldimesitylborane. In the present study, we explored the role of the $\pi$-bridge in our $\mathrm{A}-\pi-\mathrm{A}$ system, employing 4,4'-biphenyl, 2,7-pyrenyl, 2,7-fluorenyl, 3,6-carbazolyl and 5,5'-di(thien-2-yl)-3,6-diketopyrrolopyrrolyl bridges. We thus introduced more rigid $\pi$-bridges, to compare with the biphenyl compound $\mathbf{1} \mathbf{M}$, to achieve more planar ground state structures, resulting in a better delocalized $\pi$-system and therefore enhanced TPA/TPEF properties. Furthermore, enhanced donor character was introduced into the $\pi$-bridge via the carbazole, while incorporation of the dithienyldiketopyrrolopyrrole moiety leads to an A-D-A-D-A-type chromophore, allowing enhanced intramolecular charge transfers. The diketopyrrolopyrrole moiety is known for its high photostability and TPA cross-section, ${ }^{118,119}$ e.g. when connected to two porphyrin groups (up to $4000 \mathrm{GM} @ 910 \mathrm{~nm}$ in $\mathrm{CH}_{2} \mathrm{Cl}_{2}$ ). ${ }^{\mathbf{1 2 0 , 1 2 1}}$

In order to synthesize the desired water-soluble tetraammonio chromophores $\mathbf{1} \mathbf{M}-\mathbf{5} \mathbf{M}$ it was necessary to prepare their neutral tetra-amino precursors 1-5. Compounds 1-5, containing four strong $\pi$-donor $\mathrm{Me}_{2} \mathrm{~N}$ groups conjugated with the boron acceptor moieties, exhibit entirely different photophysical properties than those of their tetra-methylated derivatives. As the neutral compounds 1-5 are fundamentally interesting in their own right, we first describe their behaviour before that of the tetracationic chromophores of interest for imaging purposes.

\section{Results and discussion}

\section{Synthesis}

The synthesis of the neutral compounds 1-5 was achieved via Suzuki-Miyaura coupling of the different dibrominated $\pi$ bridges with our borylated triarylborane $6^{117}$ using $\mathrm{Pd}_{2}(\mathrm{dba})_{3}$ as the catalyst, SPhos as the ligand and $\mathrm{KOH}$ as the base
(Scheme 3). The neutral compounds were methylated with MeOTf in dichloromethane and the products $\mathbf{1} \mathbf{M}-\mathbf{3 M}$ precipitated in almost quantitative yields. The methylation needs to be carried out in basic glassware, such as soda-lime glass, as otherwise the reaction does not go to completion, and the product is contaminated with the compound in which only three of the amine groups are methylated. When using the two Boc-protected bridges, carbazole 4 and dithienyldiketopyrrolopyrrole $\mathbf{5}$, the reaction time needs to be carefully controlled, as too short a reaction time leads to incomplete methylation, whereas too long a reaction time results in deprotection and subsequent methylation of the amine in the bridge. The latter two Boc-protected tetracationic compounds were subsequently deprotected with triflic acid to yield the final compounds $\mathbf{4 M}$ and $\mathbf{5} \mathbf{M}$.

\section{Linear optical properties and TD-DFT calculations of the neutral precursors $1-5$}

The neutral chromophores behave in a very similar manner, with the exception of compound 5 . The absorption spectra of 14 (Fig. 1 and S1, $\$$ Table 1) show a low energy band corresponding to charge transfer from the $N, N$-dimethylaminoxylyl donor to the $\pi$-bridge and boron acceptor, as confirmed by TDDFT calculations, vide infra. As compounds 1-4 are so similar, we discuss compound $\mathbf{1}$ in detail as an example. Thus, for the biphenyl compound $\mathbf{1}$, the above described absorption band occurs at $392 \mathrm{~nm}$ (calculated at $354 \mathrm{~nm}$ ) resulting from the coincidental overlap of the weak $S_{1} \leftarrow S_{0}$ and stronger $S_{2} \leftarrow S_{0}$ transitions (Table 2). The HOMO-1 and HOMO are nearly degenerate, and both orbitals are localized at the $\mathrm{N}, \mathrm{N}$-dimethylaminoxylyl groups, while the LUMO and LUMO+1 are located at the $\pi$-bridge and the boron atoms (Fig. 2). The higher energy absorption bands have charge-transfer character, but with increasing energy the $\pi-\pi^{*}$ character at the $\pi$-bridge becomes increasingly dominant. The $S_{3} \leftarrow S_{0}$ and $S_{5} \leftarrow S_{0}$ transitions at 372 and $328 \mathrm{~nm}$, respectively, were calculated to be at 335 and $296 \mathrm{~nm}$, with contributions of HOMO-4 of 11 and $55 \%$, respectively (Table 2 ). HOMO-4 is delocalized over the

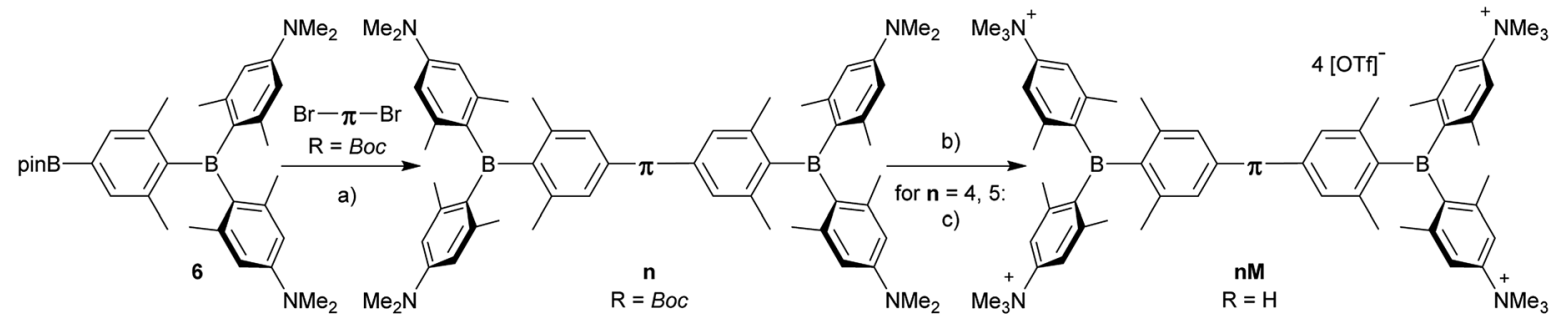

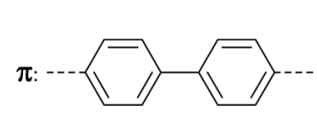

1

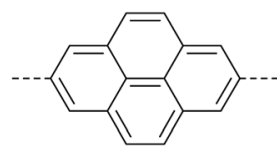

2

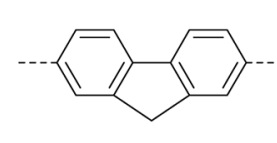

3

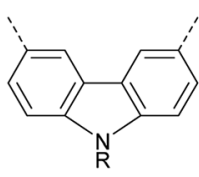

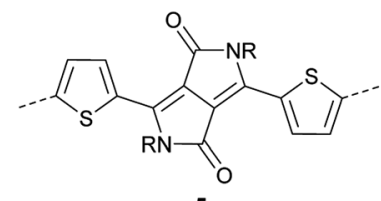

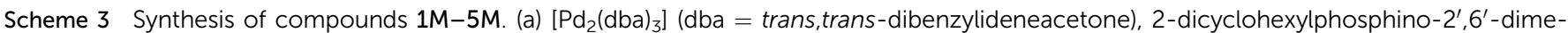
thoxybiphenyl (SPhos), $\mathrm{KOH}$, toluene, $\mathrm{H}_{2} \mathrm{O}, 85^{\circ} \mathrm{C}$; (b) $\mathrm{MeOTf}, \mathrm{CH}_{2} \mathrm{Cl}_{2}$; (c) $\mathrm{TfOH}, \mathrm{MeOH}$. 

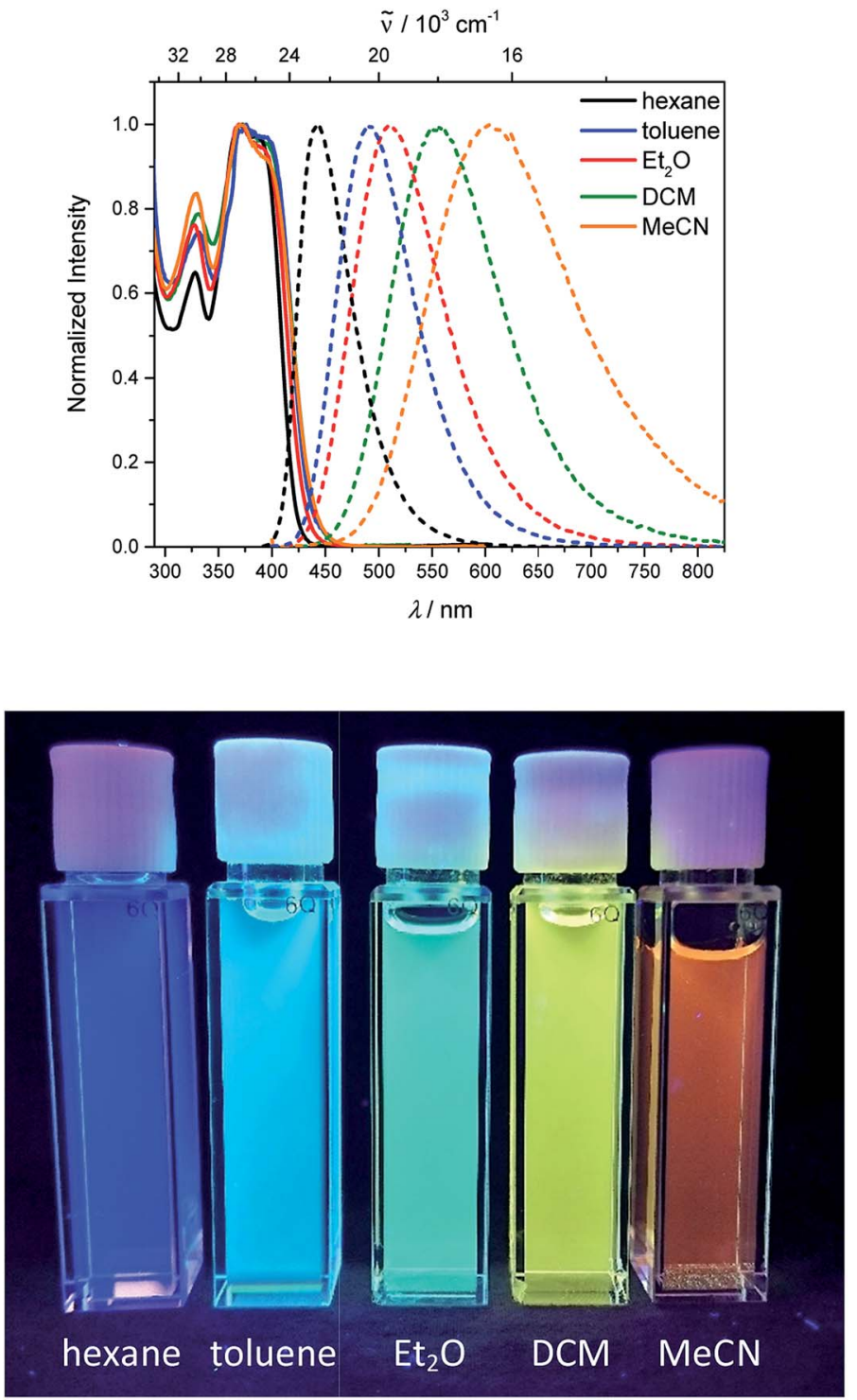
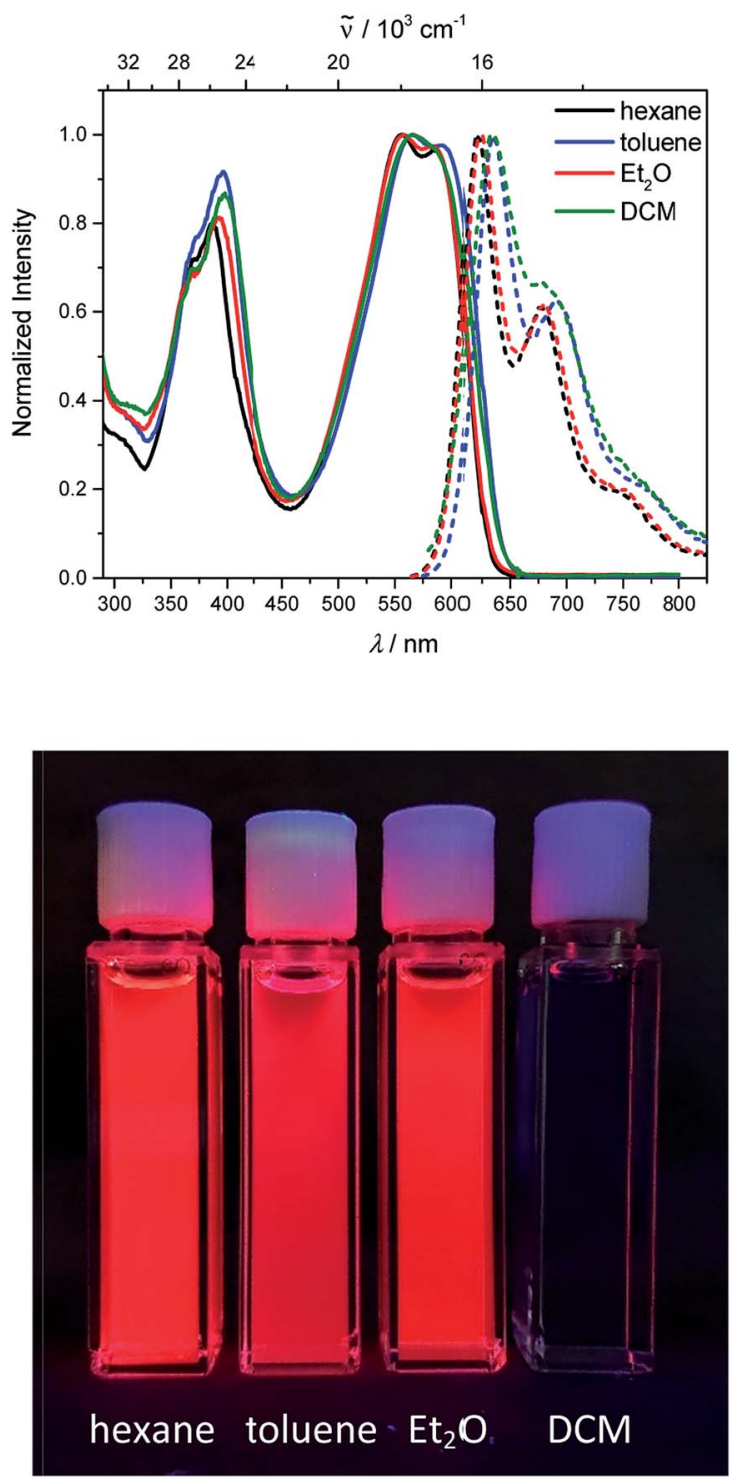

Fig. 1 Absorption and emission spectra (top) and pictures of the solutions under UV irradiation (bottom) of 1 (left) and 5 (right) in various solvents (hexane: black, toluene: blue, diethylether: red, dichloromethane: green, $\mathrm{MeCN}$ : orange).

whole $\pi$-bridge (Fig. 2). Very similar results were calculated for compounds 2-4. All compounds show different high energy absorption bands, as the $\pi-\pi^{*}$ contributions of the $\pi$-bridges become more and more important. For example, compound 2 shows one additional absorption band at $342 \mathrm{~nm}$, which is calculated to arise from the $\mathrm{S}_{6} \leftarrow \mathrm{S}_{0}$ transition from HOMO-6 to LUMO, and is a classic pyrene $\pi-\pi^{*}$ transition, with the typical nodal plane through the 2,7-positions (Fig. S3 $\ddagger$ ). ${ }^{35,36,122,123}$ The dithienyl-diketopyrrolopyrrole dye $\mathbf{5}$ is an exception, as the HOMO is located at the $\pi$-bridge (Fig. 2). Therefore, the $\mathrm{S}_{1} \leftarrow \mathrm{S}_{0}$ transition is a locally excited (LE) HOMO to LUMO transition at the $\pi$-bridge, while higher energy transitions show the same charge transfer character as noted above for 1-4 (Table 2). For 5, the HOMO-1 and HOMO-2 are nearly degenerate and are each localized at two $\mathrm{N}, \mathrm{N}$-dimethylaminoxylyl groups. Note that the TD-DFT calculations were carried out for the geometry optimized (lowest energy) structure and not for the highest possible symmetry $\left(C_{\mathrm{i}}\right)$ of these molecules. Therefore, the corresponding $\mathrm{S}_{2} \leftarrow \mathrm{S}_{0}$ and $\mathrm{S}_{4} \leftarrow \mathrm{S}_{0}$ transitions are isoenergetic and exhibit charge transfer character from the nitrogens to the boron atom.

As the lowest energy absorption bands of 1-4 have chargetransfer character, their emission spectra display strong solvatochromism. Upon going from nonpolar hexane $\left(\lambda_{\mathrm{em}, \max }=\right.$ $442 \mathrm{~nm}$ ) to polar $\mathrm{MeCN}\left(\lambda_{\mathrm{em}, \max }=603 \mathrm{~nm}\right)$, the emission maximum of 1 is bathochromically shifted by $6040 \mathrm{~cm}^{-1}$, which results in an increase of the Stokes shift by $6100 \mathrm{~cm}^{-1}$, i.e., from 4300 to $10400 \mathrm{~cm}^{-1}$ (Fig. 1 and Table 1). This positive solvatochromism with increasing solvent polarity results from a large dipole moment in the excited state. As the lowest energy absorption band results from $N, N$-dimethylaminoxylyl-to-boron charge transfer for 1-4, which all of those compounds have in 
Table 1 Photophysical data of the compounds 1 and 5 in various solvents

\begin{tabular}{|c|c|c|c|c|c|c|c|c|c|}
\hline & solvent & $\lambda_{\mathrm{abs}} / \mathrm{nm}$ & $\varepsilon / \mathbf{M}^{-1} \mathrm{~cm}^{-1}$ & $\lambda_{\mathrm{em}} / \mathrm{nm}$ & Stokes shift $/ \mathrm{cm}^{-1}$ & $\Phi_{\mathrm{f}}$ & $\tau / \mathrm{ns}$ & $k_{\mathrm{r}} / 10^{8} \mathrm{~s}^{-1}$ & $\mathrm{k}_{\mathrm{nr}} / 10^{8} \mathrm{~s}^{-1}$ \\
\hline \multirow[t]{4}{*}{1} & Hexane & 372 & \multirow[t]{4}{*}{69000} & 442 & 4300 & 0.14 & 1.5 & 0.9 & 5.8 \\
\hline & Toluene & 376 & & 493 & 6300 & 0.20 & 3.4 & 0.6 & 2.3 \\
\hline & DCM & 373 & & 556 & 8800 & 0.30 & 8.8 & 0.3 & 0.8 \\
\hline & MeCN & 371 & & 603 & 10400 & 0.08 & 2.5 & 0.3 & 3.7 \\
\hline \multirow[t]{2}{*}{5} & Hexane & 557 & \multirow[t]{2}{*}{59000} & 622 & 1900 & 0.57 & 2.4 & 2.4 & 1.8 \\
\hline & DCM & 568 & & 635 & 1900 & 0.004 & 2.3 & 0.02 & 4.3 \\
\hline
\end{tabular}

common, the emission spectra are identical regardless of the nature of the $\pi$-bridge. The emission band of 4 is slightly blueshifted, as the LUMO is a little higher in energy $(\sim 0.15 \mathrm{eV})$ than for 1-3. The LUMO of compound 4 is more localized at the boron than the bridge, because the carbazole bridge also acts as a donor. The fluorescence quantum yields and lifetimes are essentially the same for 1-4 (Table 1 and S1:). Interestingly, they do not follow the expected dependence on solvent polarity. Thus, with increasing solvent polarity, the excited state is more stabilized as shown by the bathochromic shift of the emission maximum. As $\Delta G^{00}$ decreases, following the energy gap law, ${ }^{124}$ it is expected that the nonradiative decay constant $k_{\mathrm{nr}}$ should increase and therefore the quantum yield should decrease. Our compounds 1-4 show the opposite behaviour. With increasing solvent polarity, the nonradiative decay constant decreases and the quantum yield is enhanced. Also, the experimentally determined fluorescence lifetimes increase with increasing solvent polarity, while the radiative decay constants $k_{\mathrm{r}}$ decrease with decreasing emission energy in qualitative accordance with the Strickler-Berg equation. ${ }^{125}$ This formula predicts a proportionality of the radiative decay constant $k_{\mathrm{r}}$ with the cube of the fluorescence wavenumber $\tilde{v}_{\mathrm{f}}^{3}$. Furthermore, in MeCN, compounds 1-4 do not follow the aforementioned trend. In this solvent, the quantum yields are smaller, and the fluorescence lifetimes shorter compared with DCM solutions. This behaviour was observed previously for nitrogen donor - boron acceptor compounds ${ }^{43,126-128}$ and has its origin in symmetry breaking in the excited state. The symmetry breaking is more enhanced in polar solvents than nonpolar solvents, leading to the unusual solvent behaviour seen above. ${ }^{129}$ The dithienyl-diketopyrrolopyrrole dye 5 is again an exception. As the low-energy absorption is an LE transition, this compound shows no solvatochromism in the solvents examined. In all solvents it emits pink light $(\sim 630 \mathrm{~nm})$, and the quantum yield is $c a$. 0.55 , but drops significantly in DCM, as the non-radiative decay rate rises.

\section{Linear optical properties and TD-DFT calculations of the tetracationic chromophores $1 \mathrm{M}-\mathbf{5 M}$}

Upon methylation of the neutral precursors 1-5, and subsequent deprotection of $\mathbf{4}$ and $\mathbf{5}$, the charge transfer from the amine to the boron moiety is no longer present, so the linear optical properties of the chromophores $\mathbf{1 M - 5 M}$ are completely different from those of 1-5. Fig. 3 shows the absorption spectra of $\mathbf{1 M - 5 M}$ in water. Due to solubility issues, compound $\mathbf{2 M}$ was dissolved in $10 \% \mathrm{MeCN}$ in water. The various absorption bands are attributed to the $\pi-\pi^{*}$ transitions of the individual $\pi$ bridges. TD-DFT calculations show that the computed lowenergy absorption bands at 338, 351, 335, 346 and $544 \mathrm{~nm}$,

Table 2 TD-DFT-calculated photophysical data for 1 and 5 at the CAM-B3LYP/6-31G(d) level in hexane ${ }^{a}$

\begin{tabular}{|c|c|c|c|c|}
\hline & Transition $(f)$ & $E / \mathrm{eV}^{b}$ & $\lambda / \mathrm{nm}^{b}$ & Dominant components ${ }^{c}$ \\
\hline \multirow[t]{3}{*}{1} & $\mathrm{~S}_{1} \leftarrow \mathrm{S}_{0}(0.054)$ & $3.50(3.16)$ & $354(392)$ & $\begin{array}{l}\text { LUMO }+1 \leftarrow \text { HOMO-1 }(44 \%) \\
\text { LUMO } \leftarrow \text { HOMO }(38 \%)\end{array}$ \\
\hline & $\mathrm{S}_{3} \leftarrow \mathrm{S}_{0}(1.496)$ & $3.70(3.33)$ & $335(372)$ & $\begin{array}{l}\text { LUMO } \leftarrow \text { HOMO }-4(11 \%), \text { LUMO }+1 \leftarrow \text { HOMO }-3(29 \%) \\
\text { LUMO } \leftarrow \text { HOMO }-2(37 \%)\end{array}$ \\
\hline & $\mathrm{S}_{5} \leftarrow \mathrm{S}_{0}(0.778)$ & $4.19(3.78)$ & $296(328)$ & LUMO $\leftarrow$ HOMO $-4(55 \%)$, LUMO $+1 \leftarrow$ HOMO $-3(15 \%)$ \\
\hline & $\mathrm{S}_{4} \leftarrow \mathrm{S}_{0}(0.260)$ & $3.38(3.20)$ & $367(388)$ & $\begin{array}{l}\text { LUMO } \leftarrow \text { HOMO-1 }(28 \%), \text { LUMO }+1 \leftarrow \text { HOMO }-1(24 \%) \\
\text { LUMO }+2 \leftarrow \text { HOMO-1 }(26 \%) \\
\text { LUMO }+3 \leftarrow \text { HOMO-1 }(13 \%)\end{array}$ \\
\hline
\end{tabular}

${ }^{a}$ Transitions with modest to high oscillator strength $f$ are displayed in this table. Others are shown in the ESI. ${ }^{b}$ Values in parentheses are experimental absorption maxima in hexane. ${ }^{c}$ Components with greater than $10 \%$ contribution shown. Percentage contribution approximated by $2 \times\left(c_{\mathrm{i}}\right)^{2} \times 100 \%$, where $c_{\mathrm{i}}$ is the coefficient for the particular 'orbital rotation'. 


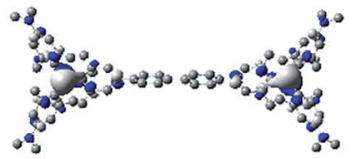

LUMO+1 (-0.16 eV)

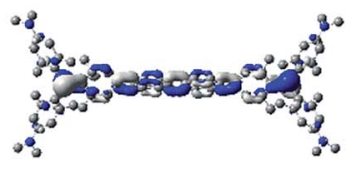

LUMO (-0.33 eV)

HOMO (-6.17 eV)

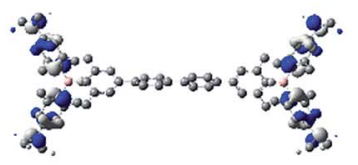

HOMO-1 (-6.17 eV)

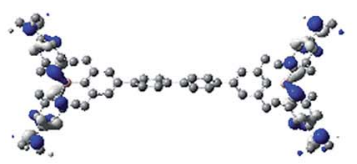

HOMO-2 (-6.34 eV)

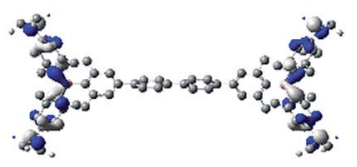

HOMO-3 (-6.35 eV)

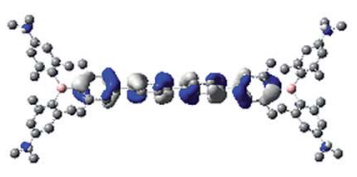

HOMO-4 (-6.61 eV)

1

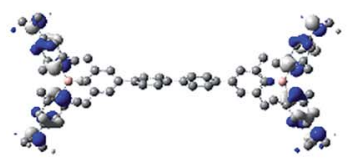

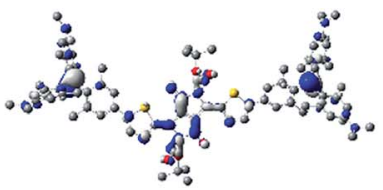

LUMO+3 (0.02 eV)

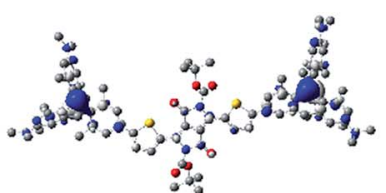

LUMO+2 (-0.22 eV)

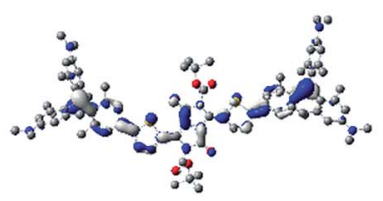

LUMO+1 (-0.55 eV)

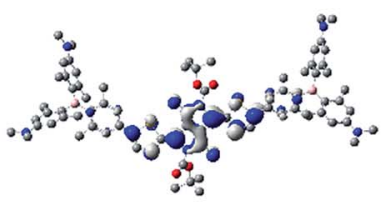

LUMO (-1.71 eV)

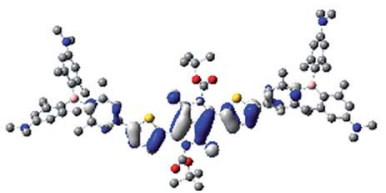

HOMO (-6.02 eV)

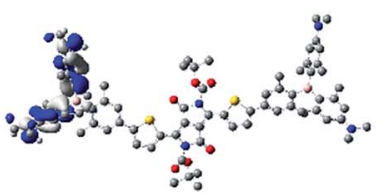

HOMO-1 (-6.19 eV)

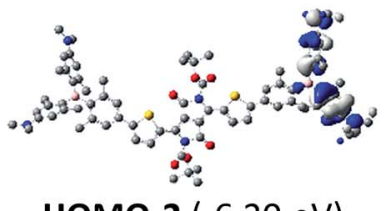

HOMO-2 (-6.20 eV)

5
Fig. 2 DFT (CAM-B3LYP/6-31G(d))-calculated relevant orbitals for 1 and 5 . Hydrogen atoms are omitted for clarity. Surface isovalue: \pm 0.03 $\left[e a_{0}{ }^{-3}\right]^{1 / 2}$. Orbital energy differences are not direct approximations of excitation energies. They are provided here for comparison between the compounds.

respectively, for $\mathbf{1 M - 5 M}$ (experimentally: 363, 375, 361, 376 and $594 \mathrm{~nm}$, respectively) are located on the $\pi$-bridge (Table 4 and Fig. 4 and 5). For the biphenyl (1M) and fluorene (3M) compounds, this is an $\mathrm{S}_{1} \leftarrow \mathrm{S}_{0}$ transition, with LUMO $+1 \leftarrow$
HOMO-1 and LUMO $\leftarrow$ HOMO contributions, where the HOMO and HOMO -1 are located at the $\pi$-bridge and the LUMO and LUMO+1 are mostly localized at the boron atoms (Table 4 and Fig. 4). Pyrene derivative $\mathbf{2} \mathbf{M}$ has the same behaviour, but the transition is $S_{2} \leftarrow S_{0}$ with the main contributions being LUMO $+1 \leftarrow$ HOMO -2 and LUMO $\leftarrow$ HOMO-1. As the HOMO is located only at the pyrene, and has a nodal plane through the substituted 2,7-positions, it does not take part in the first allowed, low energy, transition. The LUMO $+2 \leftarrow$ HOMO transition is the $\mathrm{S}_{4} \leftarrow \mathrm{S}_{0}$ absorption, which is a higher energy absorption band of $\mathbf{2 M}$ at $316 \mathrm{~nm}$ (experimentally: $342 \mathrm{~nm}$ ) (Table S10 and Fig. 4). In the case of the carbazole-bridged derivative $\mathbf{4 M}$, the calculations indicate that the $\mathrm{S}_{1} \leftarrow \mathrm{S}_{0}$ absorption has LUMO $\leftarrow$ HOMO-5 (11\%), LUMO+1 $\leftarrow$ HOMO-2 (12\%), LUMO+1 $\leftarrow$ HOMO-1 (16\%) and LUMO $\leftarrow$ HOMO (48\%) contributions. For $\mathbf{1} \mathbf{M}-\mathbf{4 M}$, the HOMOs which contribute are located at the $\pi$-bridges and LUMO and LUMO+1 are mainly localized at the boron atom. The $\mathrm{S}_{1} \leftarrow \mathrm{S}_{0}$ transition of the dithienyl-diketopyrrolopyrrole dye $\mathbf{5 M}$ is a simple LUMO $\leftarrow$ HOMO LE transition localized at the $\pi$-bridge, with a small contribution from the borons. Due to the strong acceptor strength of the boron moiety, which lowers the energies of the virtual orbitals, the low-energy absorption maxima are redshifted by up to $4334 \mathrm{~cm}^{-1}$ compared with those of the analogous compounds 1A-5A (Scheme 4). Compounds 1A-4A were previously reported, ${ }^{122,130-132}$ whereas compound $\mathbf{5 A}$ was synthesized as part of the present study.

As the nature of the transitions vary somewhat for the various $\pi$-bridges, the emission colour can be tuned from blue to pink (Fig. 3). The emission maxima shift from $467 \mathrm{~nm}$ (2M) to $620 \mathrm{~nm}(5 \mathrm{M})$ and follow the trend of the HOMO energy, as the LUMO energy stays nearly constant and is mainly boron centred (except for $\mathbf{5 M}$ ). Furthermore, for compound $\mathbf{2 M}$ the HOMO-1 needs to be considered, as the HOMO is only localized on the pyrene and is not involved in the strongest low-energy $S_{2} \leftarrow S_{0}$ excitation $\left(\mathrm{S}_{1} \leftarrow \mathrm{S}_{0}\right.$ has an oscillator strength near zero). The higher the HOMO energy, the more bathochromically shifted the emission band. Our variety of $\pi$-bridged water-soluble, quadrupolar three-coordinate boron chromophores thus provides a wide colour range spanning most of the visible spectrum. Furthermore, the compounds are not solvatochromic, as shown in Fig. 3 for $\mathbf{1} \mathbf{M}$ as an example. This proves that the transitions do not involve a significant change in dipole moment.§ The only observed effect is a broadening of the emission spectra in more polar solvents. Using Jortner's theory, ${ }^{133}$ the full width at half maximum of the bell-shaped curve of a transition depends on the reciprocal value of the reorganization energy of the solvent, so the broadening of the emission bands in more polar solvents is expected. The strong $\pi$-acceptor boron moieties also shift the emission maxima compared to those of the non-boron analogues 1A-5A (Scheme 4) between 509 and $8916 \mathrm{~cm}^{-1}$, depending on the contribution of the boron atoms.

The fluorescence quantum yields and lifetimes were measured in aqueous solution (Table 3). As the fluorescence of the carbazole compound $\mathbf{4 M}$ is very weak in aqueous solution, the lifetime could not be determined. For all other compounds 

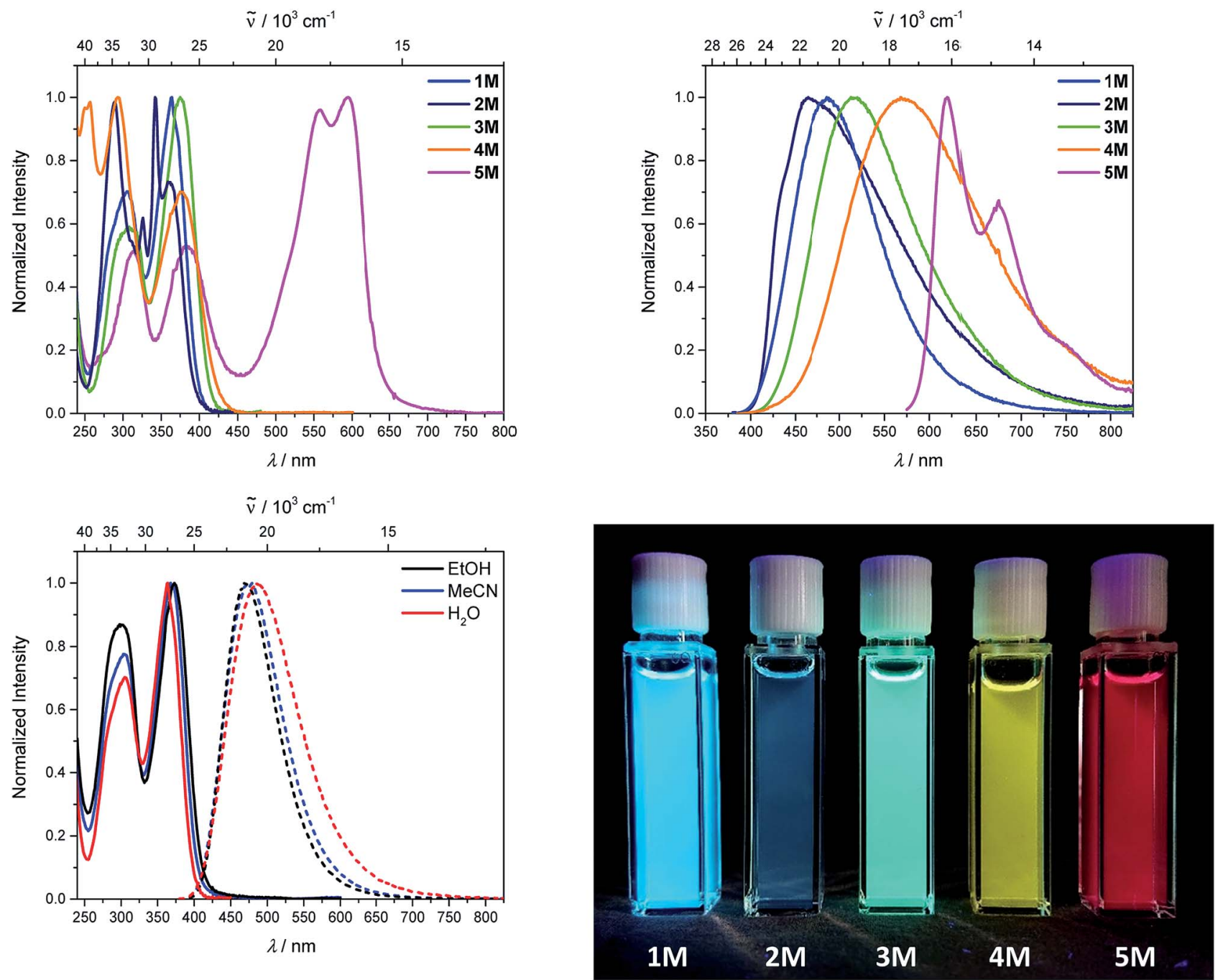

Fig. 3 Absorption (top, left) and emission spectra (top, right) of $1 \mathrm{M}-5 \mathrm{M}$ in water. Compound $2 \mathrm{M}$ was dissolved in $10 \% \mathrm{MeCN}$ in water. Absorption and emission spectra of $1 \mathrm{M}$ in various solvents ( $\mathrm{EtOH}$ : black, $\mathrm{MeCN}$ : blue, $\mathrm{H}_{2} \mathrm{O}$ : red) (bottom, left) and picture of the solutions of $1 \mathrm{M}-5 \mathrm{M}$ in $\mathrm{MeCN}$ under UV irradiation.

1M-3M and $\mathbf{5 M}$ the radiative and non-radiative decay constants were calculated and the radiative decay constants are very similar for all compounds, except for $\mathbf{2 M}$. This may be due to the use of $10 \% \mathrm{MeCN}$ to improve solubility. The variation in the quantum yields is thus due to differences in the non-radiative decay rates. Apart from $\mathbf{4 M}$, all compounds show remarkably high fluorescence quantum yields in aqueous solution, especially compound $\mathbf{1 M}$. In other solvents such as EtOH or MeCN, the fluorescence quantum yields increase, as the non-radiative decay rates decrease or the radiative decay rates increase for all compounds.

\section{Two-photon absorption}

We measured the two-photon absorption spectra of $\mathbf{1 M - 5 M}$ in $\mathrm{MeCN}$, as the polarity within cells is more similar to MeCN than to water, ${ }^{\mathbf{1 3 4}, \mathbf{1 3 5}}$ using the two-photon excited fluorescence technique. Following the electronic selection rules for centrosymmetric molecules ( $C_{\mathrm{i}}$ symmetry), 1M, 2M and 5M, the TPA maximum does not occur at the one-photon absorption maximum, as the $\mathrm{S}_{1} \leftarrow \mathrm{S}_{0}$ transition $\left(\mathrm{A}_{\mathrm{u}} \leftarrow \mathrm{A}_{\mathrm{g}}\right.$ symmetry) is symmetry forbidden for two-photon absorption, but is located at higher energy where TPA allowed transitions of $A_{g} \leftarrow A_{g}$ symmetry occur $\left(S_{2} \leftarrow S_{0}\right.$ transition for $\mathbf{1 M}$ and $\mathbf{5 M}$ and $S_{3} \leftarrow S_{0}$ transition for $\mathbf{2 M}$ ). The other two molecules $3 \mathbf{M}$ and $\mathbf{4 M}$ have $C_{2 \mathrm{v}}$ as their highest possible symmetry, thus lacking an inversion centre, which is why all transitions are one- and two-photon allowed. Therefore, we applied $C_{\mathrm{i}}$ symmetry for $\mathbf{1} \mathbf{M}, \mathbf{2 M}$ and $\mathbf{5 M}$ and performed TD-DFT calculations (Table 4, red), to obtain more insight into which transitions are one- and or twophoton allowed. In Fig. 6, in which the TPA and rescaled onephoton absorption (OPA) are compared, for $\mathbf{1 M}$ we observed a TPA maximum at $720 \mathrm{~nm}$, corresponding to $S_{2} \leftarrow S_{0}$ which has $A_{g}$ symmetry, and therefore is two-photon allowed but onephoton forbidden. The first excited state is, however, slightly TPA allowed as indicated by the shoulder, because of vibrational coupling of the $A_{u}$ state with an $a_{u}$ vibrational mode, which makes the overall wavefunction gerade. ${ }^{136,137}$ From 
LUMO+1

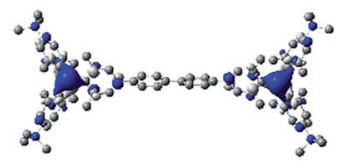

$-1.20$

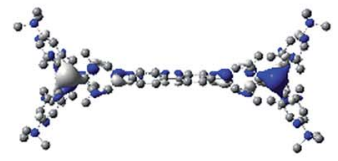

$-1.29$

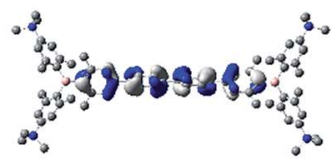

$\mathrm{E} / \mathrm{eV}$

HOMO-1

$\mathrm{E} / \mathrm{eV}$

HOMO-2

$\mathrm{E} / \mathrm{eV}$

HOMO-5

$\mathrm{E} / \mathrm{eV}$

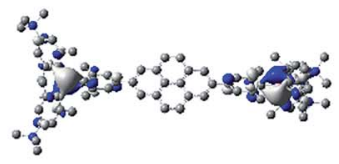

$-1.21$

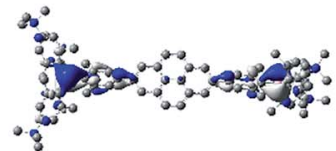

$-1.31$

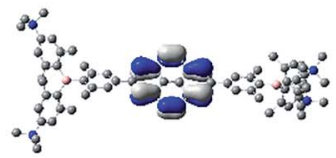

$-6.81$

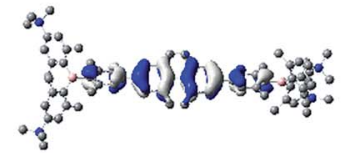

$-7.19$

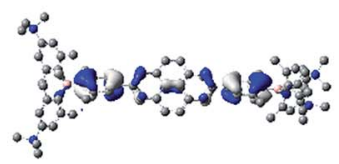

$-7.93$

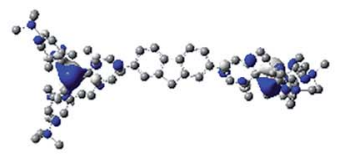

$-1.20$

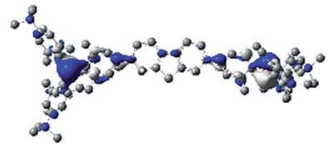

$-1.31$

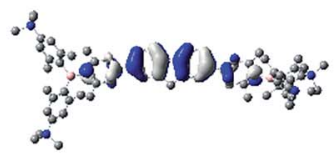

$-6.90$

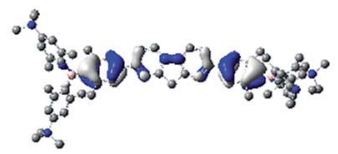

$-7.85$

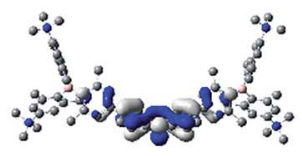

$-6.75$

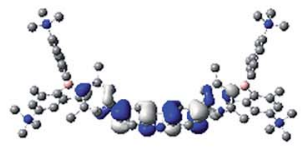

$-7.21$

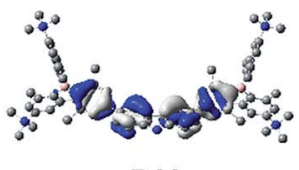

$-7.90$

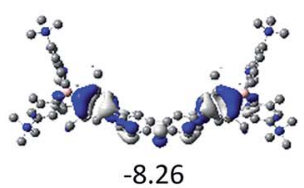

$4 \mathrm{M}$

Fig. 4 DFT (CAM-B3LYP/6-31G(d))-calculated relevant orbitals for 1M-4M. Hydrogen atoms are omitted for clarity. Surface isovalue: \pm 0.03 [ea $\left.{ }^{-3}\right]^{1 / 2}$.

calculations on $\mathbf{2 M}$ in $C_{\mathrm{i}}$ symmetry, we can assign the twophoton allowed transition to the $\mathrm{S}_{3} \leftarrow \mathrm{S}_{0}$ transition $\left(\mathrm{A}_{\mathrm{g}} \leftarrow \mathrm{A}_{\mathrm{g}}\right.$ symmetry). However, the experimental spectrum shows a TPA

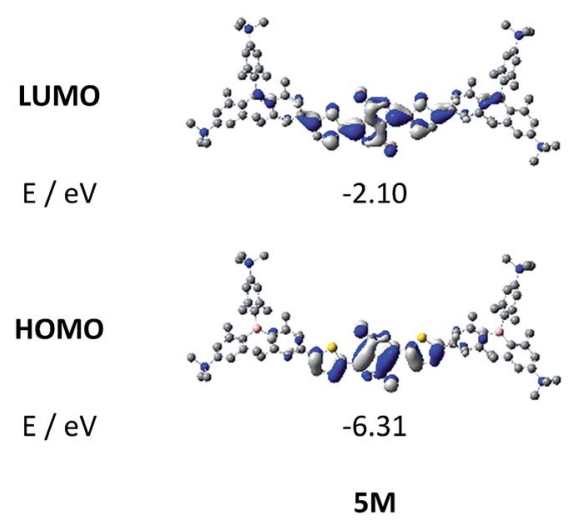

Fig. 5 DFT (CAM-B3LYP/6-31G(d))-calculated frontier orbitals for 5M. Hydrogen atoms are omitted for clarity. Surface isovalue: \pm 0.03 $\left[e a_{0}{ }^{-3}\right]^{1 / 2}$. maximum at $750 \mathrm{~nm}$, which is at the energy of the $S_{1} \leftarrow S_{0}$ transition. This transition has a very small oscillator strength $(f$ $=0.005$ ) and is therefore not observable in the OPA spectrum, although the first excited state is ungerade. It might be TPA allowed because of vibrational coupling of the $1 \mathrm{~A}_{\mathrm{u}}$ and/or $2 \mathrm{~A}_{\mathrm{u}}$ state with an $\mathrm{a}_{\mathrm{u}}$ vibrational mode, as the energy difference between $S_{1}$ and $S_{3}$ is only $1936 \mathrm{~cm}^{-1} \cdot{ }^{136,137}$ Compound $\mathbf{5 M}$ shows a TPA maximum at $740 \mathrm{~nm}$, which correlates with the second excited state. This state is gerade and therefore the transition should be only TPA allowed. Excitation to the ungerade first excited state is forbidden for the two photon process, and is therefore only observed in the OPA spectrum at $600 \mathrm{~nm}$. Vibrational coupling in this molecule is very unlikely as the first and second excited states are separated by $8308 \mathrm{~cm}^{-1} \cdot{ }^{\mathbf{1 3 6 , 1 3 7}}$ The two other molecules $\mathbf{3 M}$ and $\mathbf{4 M}$ have no inversion centres; therefore, all transitions are both OPA and TPA allowed. However, the transitions have different oscillator strengths. For compound $\mathbf{3 M}$ the TPA maximum at $730 \mathrm{~nm}$ corresponds to the $\mathrm{S}_{2}$ state, which has a higher oscillator strength for TPA than OPA. The $S_{1}$ state has a lower oscillator 

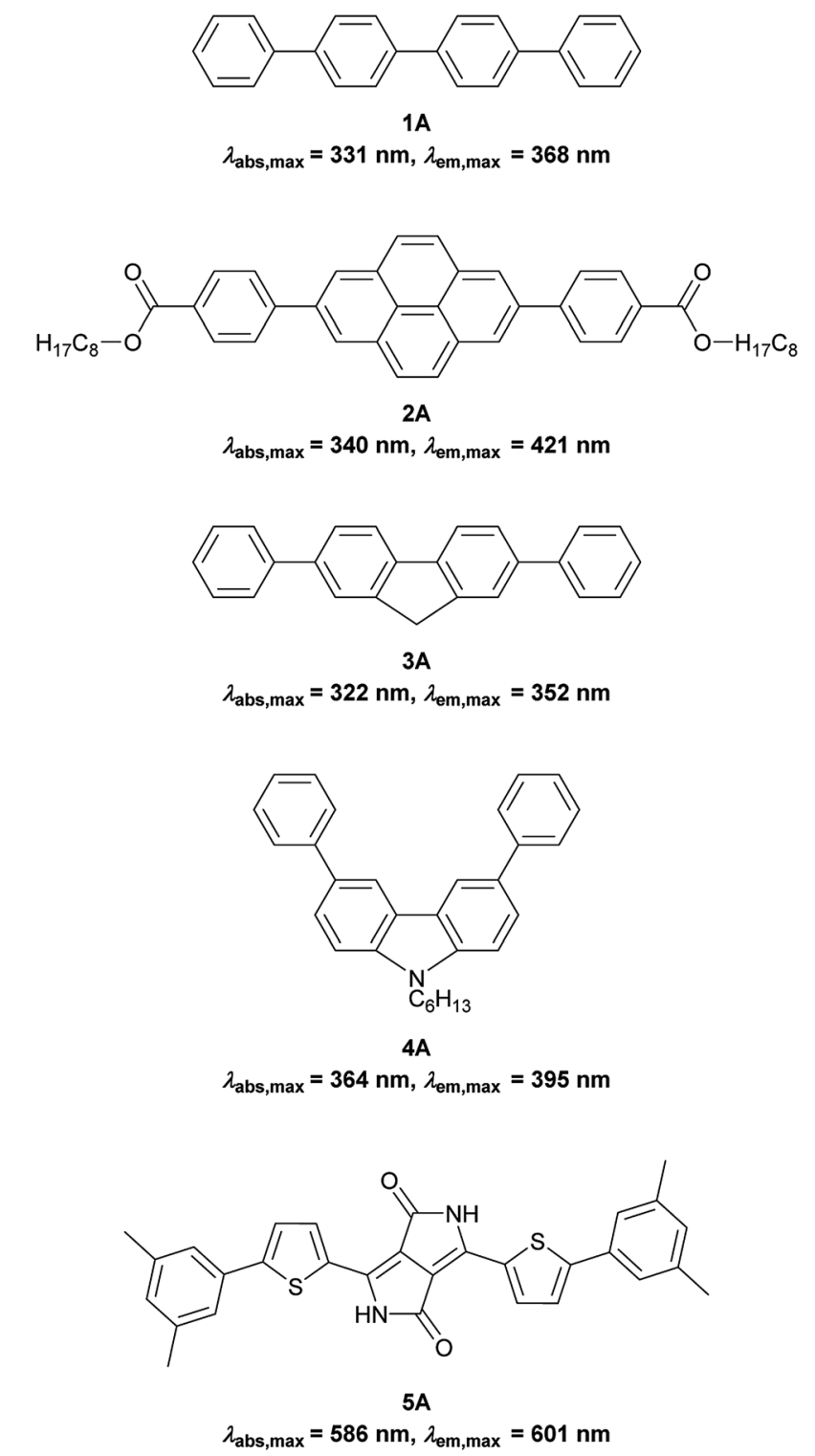

Scheme 4 Non-boron containing analogues; $1 \mathrm{~A}$ was measured in acetone, ${ }^{130} 2 \mathrm{~A}$ in toluene, ${ }^{122} 3 \mathrm{~A}$ in ethyl acetate, ${ }^{132} 4 \mathrm{~A}$ in $\mathrm{MeCN}^{131}$ and $5 \mathrm{~A}$ in DMSO.

strength for TPA and is indicated by the shoulder. For compound $\mathbf{4 M}$ the TPA maximum at $760 \mathrm{~nm}$ corresponds to the $S_{2}$ state, but the transition to the first excited state is also highly allowed. Therefore, the two-photon cross-sections for both transitions are not very different, while the one-photon cross-sections are. In the following discussion, we use the geometry-optimized structures to explain the magnitudes of the TPA cross-sections. As expected, the biphenyl compound $\mathbf{1 M}$ has the smallest TPA cross-section, being $72 \mathrm{GM}$, as this compound is the most twisted in its ground state structure (Fig. 7 and 8). The twist angles between the xylylene and phenylene rings are $c a .37^{\circ}$ and the angle between the two phenyl rings of the flexible biphenyl bridge is also $37^{\circ}$ (Table S13 $\$$ ). Conjugation within the $\pi$-system in $\mathbf{1 M}$ is less efficient due to the rotational degree of freedom around the central $\mathrm{C}-\mathrm{C}$ bond and, therefore, the TPA cross-section is reduced. With increasing planarity in $\mathbf{2} \mathbf{M}-\mathbf{4 M}$, in which two phenyl rings are rigidified by incorporation into the pyrene, fluorene or carbazole moieties, the two-photon cross-sections are increased to 79,162 , and $134 \mathrm{GM}$, respectively. The ground state structures show that the angles between the xylylene group and the $\pi$ bridge are again $c a .37^{\circ}$ for the three compounds, while the two "phenylene" rings have no twist at all, as they are constrained. To explain the rather different results for the three compounds, we must discuss the different ways, beside coplanarity, to improve the two-photon absorption crosssection. It was shown that increasing the length or efficiency of a conjugated system leads to an enhanced two-photon absorption cross-section. ${ }^{\mathbf{4 9 - 5 3}}$ Therefore, compound $\mathbf{4 M}$ should have the smallest value, as the xylylene groups are linked via the 3,6-positions rather than the 2,7-positions of the $\pi$-bridge, which leads to a less efficient conjugation. Furthermore, increasing intramolecular charge transfer enhances the two-photon absorption cross-section. ${ }^{4-53}$ It is known that $\mathrm{A}-\pi-\mathrm{D}-\pi-\mathrm{A}$ systems are more efficient than $\mathrm{A}-\pi-$ A systems. ${ }^{49-53}$ The donor-strength of the $\pi$-bridge can be correlated with the HOMO energy, which rises from pyrene $(-7.19 \mathrm{eV}(\mathrm{HOMO}-1))$ to fluorene $(-6.90 \mathrm{eV})$ to carbazole $(-6.75 \mathrm{eV})$. In the case of pyrene, the HOMO-1 must be considered as the HOMO has a nodal plane at the 2,7-positions. Therefore, the two-photon cross-section should be enhanced from pyrene $\mathbf{2 M}$, to fluorene $\mathbf{3} \mathbf{M}$ to carbazole $\mathbf{4 M}$. The latter one $\mathbf{4 M}$, however, has a shorter conjugation length than $\mathbf{3} \mathbf{M}$, and the effect of the reduced conjugation (vide supra) lowers the TPA cross-section. The dithienyldiketopyrrolopyrrole compound $\mathbf{5} \mathbf{M}$ has by far the highest two-photon absorption value, being $4560 \mathrm{GM}$. Its conjugated $\pi$-system is elongated, and the calculated ground state structure is almost planar. ${ }^{118}$ The angles between the xylylene and the thiophene groups are $15^{\circ}$, and thus much smaller than in the other compounds, and the twist between the thiophenes and the diketopyrrolopyrrole is only $2-4^{\circ}$. Furthermore, the two-photon brightness shows the same trend, with the exception that compound $\mathbf{1 M}$ has a higher value than $\mathbf{2 M}$ and $\mathbf{4 M}$, due to its much higher fluorescence quantum yield (Fig. 7). Overall, the two-photon brightness of $\mathbf{5 M}$ is exceptionally high, being 2545 GM in MeCN. Furthermore, we compared the two-photon absorption of $\mathbf{5 M}$ with its boron-free analogue 5A. While the linear optical properties (absorption and emission) of $\mathbf{5 M}$ were only slightly red-shifted compared to those of $\mathbf{5 A}$, the TPA data are quite different. The two-photon absorption cross-section of $\mathbf{5 M}$ is ca. 8.7 times higher than that of its analogue $\mathbf{5 A}$ in DMSO solution (Fig. S4 ). These data show that our boron-based acceptor moiety strongly enhances the TPA properties.

\section{Imaging}

As none of the neutral compounds 1-5 are soluble in Dulbecco's Modified Eagle Medium (DMEM), they formed nanoparticles in that medium and were not taken up by HeLa or HepG2 cells (Fig. S6 $\$$ ). In addition, pre-mixing of chromophores 1-5 with 
Table 3 One- and two-photon photophysical data of compounds $1 \mathrm{M}-5 \mathrm{M}$ in various solvents

\begin{tabular}{|c|c|c|c|c|c|c|c|c|c|c|c|}
\hline & Solvent & $\lambda_{\mathrm{abs}} / \mathrm{nm}$ & $\varepsilon / \mathbf{M}^{-1} \mathrm{~cm}^{-1}$ & $\lambda_{\mathrm{em}} / \mathrm{nm}$ & Stokes shift $/ \mathrm{cm}^{-1}$ & $\Phi_{\mathrm{f}}$ & $\tau / \mathrm{ns}$ & $k_{\mathrm{r}} / 10^{8} \mathrm{~s}^{-1}$ & $\mathrm{k}_{\mathrm{nr}} / 10^{8} \mathrm{~s}^{-1}$ & $\lambda_{\text {TPA,max }} / \mathrm{nm}$ & $\sigma_{2} / \mathrm{GM}$ \\
\hline \multirow[t]{2}{*}{$\mathbf{1 M}$} & EtOH & 373 & & 470 & 5500 & 0.71 & 4.9 & 1.4 & 0.6 & & \\
\hline & $\mathrm{MeCN}$ & 368 & 57000 & 478 & 6300 & 0.73 & 5.2 & 1.4 & 0.5 & 720 & 72 \\
\hline \multirow[t]{3}{*}{$2 \mathbf{M}$} & EtOH & 371 & & 465 & 5400 & 0.20 & 14.3 & 0.1 & 0.6 & & \\
\hline & $\mathrm{MeCN}$ & 368 & 61000 & 462 & 5500 & 0.12 & 12.6 & 0.1 & 0.7 & 750 & 79 \\
\hline & $\mathrm{H}_{2} \mathrm{O}^{a}$ & 365 & & 467 & 6000 & 0.12 & 19.5 & 0.1 & 0.4 & & \\
\hline & $\mathrm{H}_{2} \mathrm{O}$ & 375 & & 513 & 7200 & 0.33 & 3.7 & 0.9 & 1.8 & & \\
\hline \multirow[t]{3}{*}{$4 \mathbf{M}$} & EtOH & 397 & & 565 & 7500 & 0.45 & 7.4 & 0.6 & 0.7 & & \\
\hline & $\mathrm{MeCN}$ & 385 & 33000 & 568 & 8400 & 0.38 & 7.9 & 0.5 & 0.8 & 760 & 134 \\
\hline & $\mathrm{H}_{2} \mathrm{O}$ & 376 & & 568 & 9000 & 0.03 & $-^{b}$ & - & - & & \\
\hline \multirow[t]{2}{*}{$5 \mathbf{M}$} & $\mathrm{EtOH}$ & 599 & & 624 & 6700 & 0.40 & 2.2 & 1.8 & 2.7 & & \\
\hline & $\mathrm{MeCN}$ & 593 & 50000 & 617 & 6600 & 0.56 & 2.9 & 1.9 & 1.5 & 740 & 4560 \\
\hline
\end{tabular}

Pluronic F-127 was not successful. The compounds did dissolve in that medium, yet no cellular uptake was observable (Fig. S7:).

Thus, the methylated species $\mathbf{1 M - 5 M}$, designed to be watersoluble, were used for cell imaging. We treated HeLa cells with $500 \mathrm{nM}$ concentrations of all 5 compounds. Visualization with a confocal laser scanning fluorescence microscope showed cellular uptake for 1M-5M (Fig. 9 and S8-S11 ). Co-staining experiments with commercially available LysoTrackers ${ }^{\mathrm{TM}}$ confirmed their localization in acidic intracellular compartments such as endosomes and lysosomes. The Pearson values $\left(R_{\mathrm{r}}\right)$, indicative of the degree of co-localization, were all higher than 0.73 , while for $\mathbf{4 M}$ and $\mathbf{5 M}$ values of 0.83 and 0.81 , respectively, were reached. Furthermore, cell viability experiments were performed to investigate the potential of

Table 4 TD-DFT-calculated photophysical data for 1M-5M at the CAM-B3LYP/6-31G(d) level in water ${ }^{a}$

\begin{tabular}{|c|c|c|c|c|c|c|}
\hline & State & Symmetry & $f$ & $E / \mathrm{eV}$ & $\lambda / \mathrm{nm}$ & Dominant components ${ }^{b}$ \\
\hline \multirow{6}{*}{$1 \mathrm{M}$} & $\mathrm{S}_{1}$ & A & 1.709 & 3.66 & 338 & $\mathrm{H}-1 \rightarrow \mathrm{L}+1(28 \%), \mathrm{H} \rightarrow \mathrm{L}(53 \%)$ \\
\hline & $\mathrm{S}_{1}$ & $A_{u}$ & 1.857 & 3.63 & 341 & $H-1 \rightarrow L+1(26 \%), H \rightarrow L(56 \%)$ \\
\hline & $\mathrm{S}_{2}$ & $A$ & 0.000 & 3.80 & 326 & $\mathrm{H}-1 \rightarrow \mathrm{L}(38 \%), \mathrm{H} \rightarrow \mathrm{L}+1(40 \%)$ \\
\hline & $\mathrm{S}_{2}$ & $A_{g}$ & 0.000 & 3.80 & 326 & $\mathrm{H}-1 \rightarrow \mathrm{L}(37 \%), \mathrm{H} \rightarrow \mathrm{L}+1(40 \%)$ \\
\hline & $\mathrm{S}_{3}$ & $A$ & 0.013 & 4.18 & 296 & $\mathrm{H}-3 \rightarrow \mathrm{L}+1(31 \%), \mathrm{H}-2 \rightarrow \mathrm{L}(36 \%)$ \\
\hline & $\mathrm{S}_{3}$ & $\mathrm{Ag}_{\mathrm{g}}$ & 0.000 & 4.18 & 297 & $\mathrm{H}-3 \rightarrow \mathrm{L}(36 \%), \mathrm{H}-2 \rightarrow \mathrm{L}+1(31 \%)$ \\
\hline \multirow{6}{*}{$2 \mathrm{M}$} & $\overline{\mathrm{S}_{1}}$ & $\bar{A}$ & 0.004 & 3.65 & 339 & $\mathrm{H}-1 \rightarrow \mathrm{L}+2(29 \%), \mathrm{H} \rightarrow \mathrm{L}(33 \%), \mathrm{H} \rightarrow \mathrm{L}+3(28 \%)$ \\
\hline & $\mathrm{S}_{1}$ & $A_{u}$ & 0.005 & 3.51 & 354 & $H-1 \rightarrow L+2(27 \%), H \rightarrow L(39 \%), H \rightarrow L+3(25 \%)$ \\
\hline & $\mathrm{S}_{2}$ & $A$ & 1.733 & 3.69 & 335 & $\mathrm{H}-2 \rightarrow \mathrm{L}+1(30 \%), \mathrm{H}-1 \rightarrow \mathrm{L}(52 \%)$ \\
\hline & $\mathrm{S}_{2}$ & $A_{u}$ & 1.801 & 3.58 & 347 & $\mathrm{H}-2 \rightarrow \mathrm{L}+1(24 \%), \mathrm{H}-1 \rightarrow \mathrm{L}(61 \%)$ \\
\hline & $\mathrm{S}_{3}$ & $A$ & 0.012 & 3.81 & 325 & $\mathrm{H}-2 \rightarrow \mathrm{L}(38 \%), \mathrm{H}-1 \rightarrow \mathrm{L}+1(39 \%)$ \\
\hline & $\mathrm{S}_{3}$ & $\mathrm{Ag}_{\mathrm{g}}$ & 0.000 & 3.75 & 330 & $\mathrm{H}-2 \rightarrow \mathrm{L}(37 \%), \mathrm{H}-1 \rightarrow \mathrm{L}+1(43 \%)$ \\
\hline \multirow{3}{*}{ 3M } & $\overline{\mathrm{S}_{1}}$ & A & 1.905 & 3.53 & 351 & $\mathrm{H}-1 \rightarrow \mathrm{L}+1(21 \%), \mathrm{H} \rightarrow \mathrm{L}(60 \%)$ \\
\hline & $\mathrm{S}_{2}$ & A & 0.023 & 3.74 & 332 & $\begin{array}{l}\mathrm{H}-5 \rightarrow \mathrm{L}+1(11 \%), \mathrm{H}-1 \rightarrow \mathrm{L}(34 \%), \mathrm{H}-1 \rightarrow \mathrm{L}+1 \\
(44 \%)\end{array}$ \\
\hline & $\mathrm{S}_{3}$ & $\mathrm{~A}$ & 0.018 & 4.16 & 298 & $\mathrm{H}-2 \rightarrow \mathrm{L}(32 \%), \mathrm{H}-2 \rightarrow \mathrm{L}+1(24 \%)$ \\
\hline \multirow{3}{*}{$4 M$} & $\overline{\mathrm{S}_{1}}$ & $\bar{A}$ & 1.113 & 3.58 & 346 & $\begin{array}{l}\mathrm{H}-5 \rightarrow \mathrm{L}(11 \%), \mathrm{H}-2 \rightarrow \mathrm{L}+1(12 \%), \mathrm{H}-1 \rightarrow \mathrm{L}+1 \\
(16 \%), \mathrm{H} \rightarrow \mathrm{L}(48 \%)\end{array}$ \\
\hline & $\mathrm{S}_{2}$ & A & 0.298 & 3.70 & 335 & $\begin{array}{l}H-5 \rightarrow L+1(15 \%), H-2 \rightarrow L(14 \%), H-1 \rightarrow L(20 \%) \\
H \rightarrow L+1(40 \%)\end{array}$ \\
\hline & $\mathrm{S}_{3}$ & $\mathrm{~A}$ & 0.013 & 4.19 & 296 & $\mathrm{H}-3 \rightarrow \mathrm{L}(41 \%), \mathrm{H}-3 \rightarrow \mathrm{L}+1(23 \%)$ \\
\hline \multirow{6}{*}{$5 \mathrm{M}$} & $\overline{\mathrm{S}_{1}}$ & $\bar{A}$ & 1.802 & 2.28 & 544 & $H \rightarrow L(93 \%)$ \\
\hline & $\mathrm{S}_{1}$ & $A_{u}$ & 1.596 & 2.33 & 532 & $H \rightarrow L(94 \%)$ \\
\hline & $\mathrm{S}_{2}$ & $A$ & 0.138 & 3.29 & 376 & $H-1 \rightarrow L(22 \%), H \rightarrow L+1(53 \%), H \rightarrow L+3(10 \%)$ \\
\hline & $\mathrm{S}_{2}$ & $A_{g}$ & 0.000 & 3.36 & 369 & $\mathrm{H}-1 \rightarrow \mathrm{L}(25 \%), \mathrm{H} \rightarrow \mathrm{L}+1(45 \%), \mathrm{H} \rightarrow \mathrm{L}+3(11 \%)$ \\
\hline & $\mathrm{S}_{3}$ & $A$ & 0.777 & 3.57 & 347 & $\mathrm{H}-2 \rightarrow \mathrm{L}(28 \%), \mathrm{H}-1 \rightarrow \mathrm{L}+1(23 \%), \mathrm{H} \rightarrow \mathrm{L}+2(34 \%)$ \\
\hline & $\mathrm{S}_{3}$ & $A_{u}$ & 0.917 & 3.59 & 345 & $\mathrm{H}-2 \rightarrow \mathrm{L}(26 \%), \mathrm{H}-1 \rightarrow \mathrm{L}+1(24 \%), \mathrm{H} \rightarrow \mathrm{L}+2(32 \%)$ \\
\hline
\end{tabular}

\footnotetext{
${ }^{a}$ Black: without symmetry constraints, red: in $C_{\mathrm{i}}$ symmetry. ${ }^{b}$ Components with greater than $10 \%$ contribution shown. Percentage contribution
} approximated by $2 \times\left(c_{\mathrm{i}}\right)^{2} \times 100 \%$, where $c_{\mathrm{i}}$ is the coefficient for the particular 'orbital rotation'. 

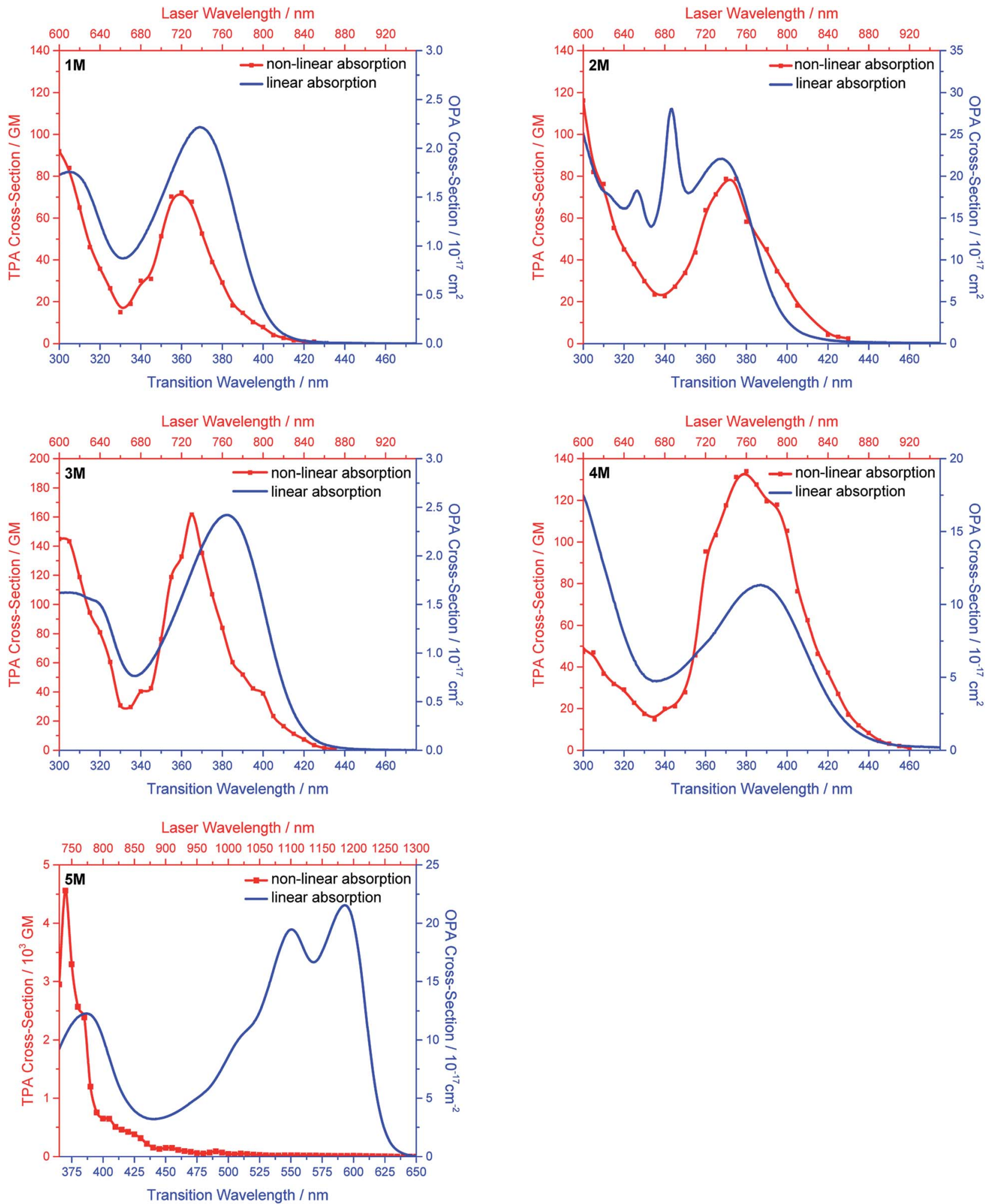

Fig. 6 One-photon absorption (blue) and two-photon absorption spectra (red) of $1 \mathrm{M}$ (first row, left), 2M (first row, right), 3M (second row, left), $4 \mathrm{M}$ (second row, right) and $5 \mathrm{M}$ (third row, left) in $\mathrm{MeCN}$.

chromophores $\mathbf{1 M - 5 M}$ for live-cell imaging. HeLa cells were treated with serial dilutions of $\mathbf{1} \mathbf{M}-\mathbf{5} \mathbf{M}$ and the cell metabolic activity was studied using a colourimetric (MTT) assay (Fig. S13 ). These confirmed that compounds $\mathbf{1} \mathbf{M}-\mathbf{5 M}$ did not influence the cell viability at concentrations as high as $5 \mu \mathrm{M}$ after $24 \mathrm{~h}$ incubation time, and some of them were non-toxic to cells even at higher concentrations $(10 \mu \mathrm{M})$. As the dithienyldiketopyrrolopyrrole dye $\mathbf{5} \mathbf{M}$ has the most red-shifted 

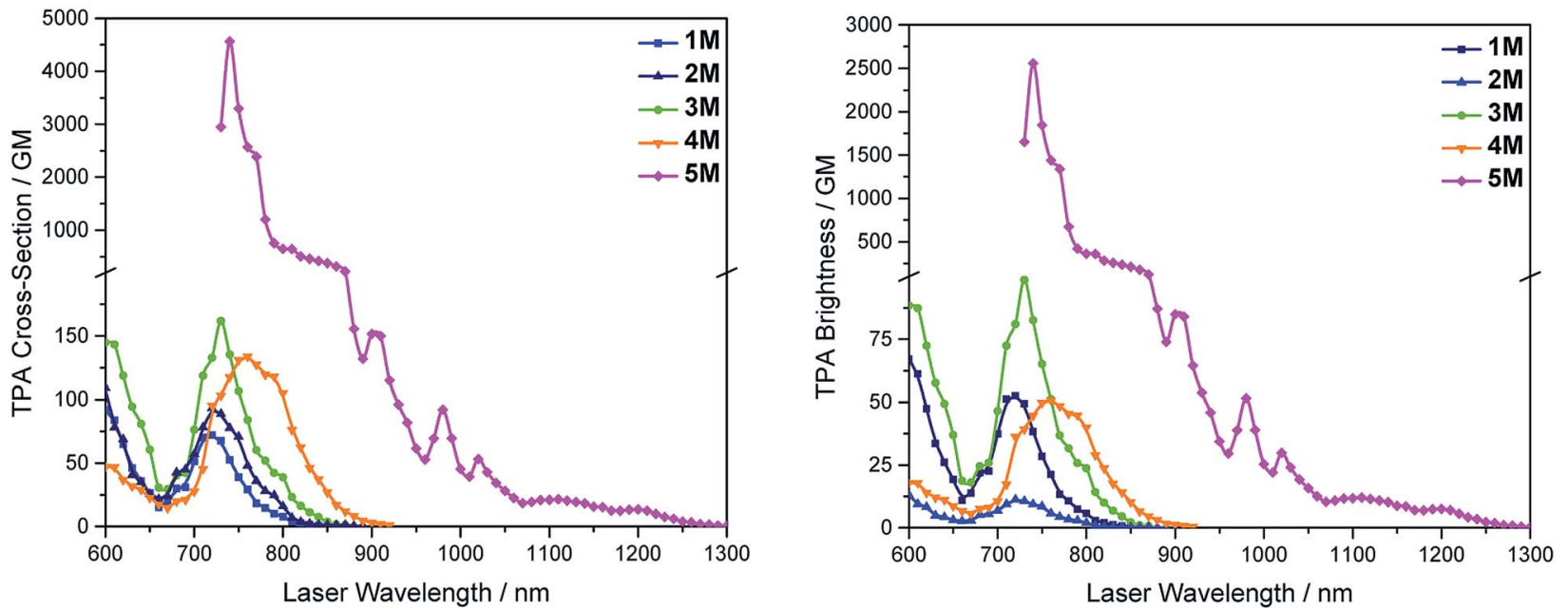

Fig. 7 Two-photon absorption spectra (left) and two-photon brightness ( $\left.\sigma_{2} \Phi_{f}\right)$ (right) of $1 \mathrm{M}-5 \mathrm{M}$ in $\mathrm{MeCN}$.

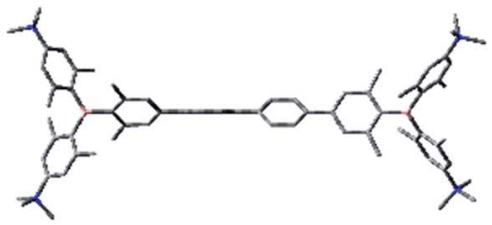

$1 \mathrm{M}$

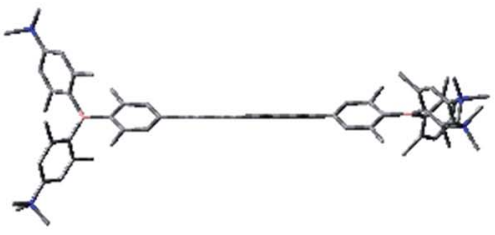

2M

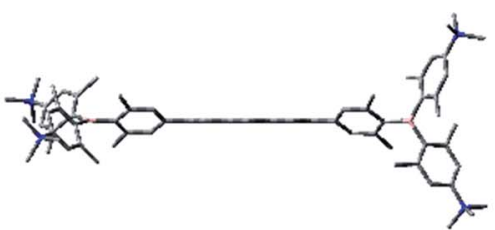

$3 \mathrm{M}$

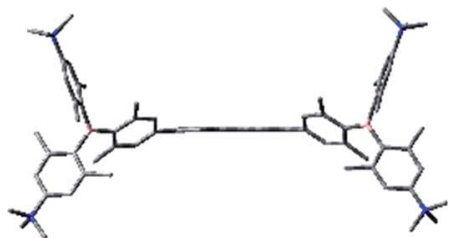

$4 \mathrm{M}$

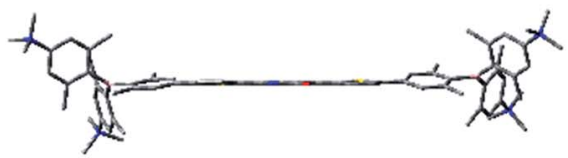

$5 \mathrm{M}$

Fig. 8 Side view of the geometries of the DFT-optimized $S_{0}$ states of $1 M-5 M$ at the B3LYP/6-31G(d) level of theory. Atom colour code: carbon (grey), boron (pink), sulphur (yellow), nitrogen (blue), oxygen (red). Hydrogen atoms are omitted for clarity. absorption and emission bands and, by far, the highest TPA cross-section and brightness, we focused on this compound for further imaging experiments.

The process by which cell internalization of our dye $5 \mathbf{M}$ takes place was observed via time-lapse confocal microscopy for $2 \mathrm{~h}$ (Fig. 10). The cultured medium of HeLa cells was replaced with the dye-containing DMEM and images were recorded every $10 \mathrm{~min}$ without any washing process. The dye first attaches to
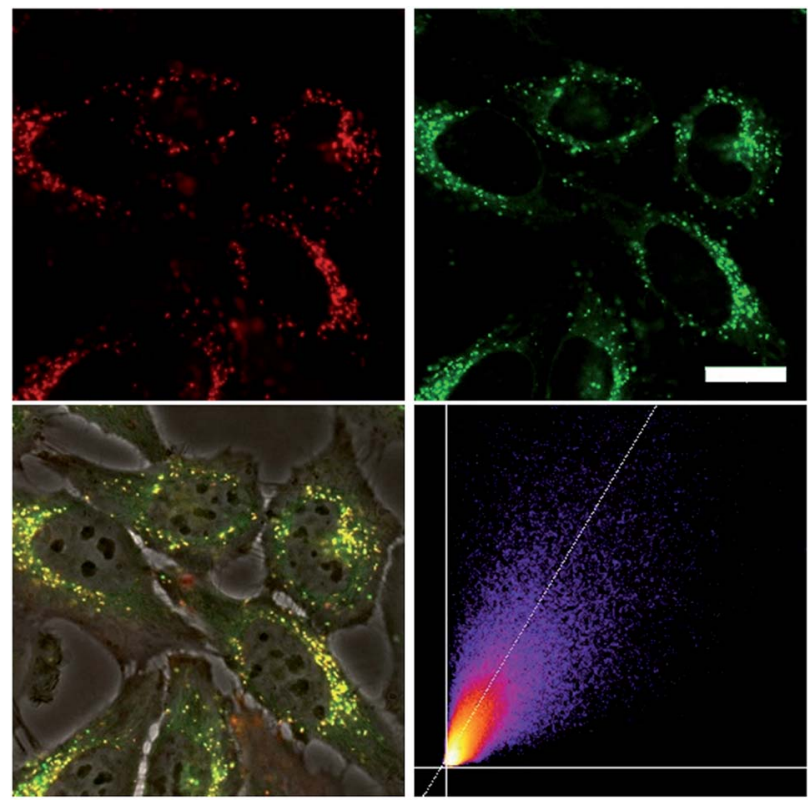

Fig. 9 Co-staining experiment of HeLa cells with $5 \mathrm{M}$ and LysoTracker ${ }^{T M}$ Green. The cells were loaded with $5 \mathrm{M}(500 \mathrm{nM}, 2 \mathrm{~h})$ and LysoTracker ${ }^{\mathrm{TM}}$ Green (100 nM, $20 \mathrm{~min}$ ) under $5 \% \mathrm{CO}_{2}$ at $37^{\circ} \mathrm{C}$. Fluorescence images of $5 \mathrm{M}$ (top, left, $\lambda_{\mathrm{ex}}=559 \mathrm{~nm} ; \lambda_{\mathrm{em}}=570-670 \mathrm{~nm}$ ) and LysoTracker' ${ }^{T M}$ Green (top, right, $\lambda_{\text {ex }}=473 \mathrm{~nm} ; \lambda_{\text {em }}=490-540$ $\mathrm{nm}$ ). The merged image of the bright field image and both fluorescence images (bottom, left), and the correlation plot of the intensities (bottom, right, $R_{\mathrm{r}}=0.81$ ), show co-localization of the dye $5 \mathrm{M}$ in the lysosomes. Scale bar: $20 \mu \mathrm{M}$. 

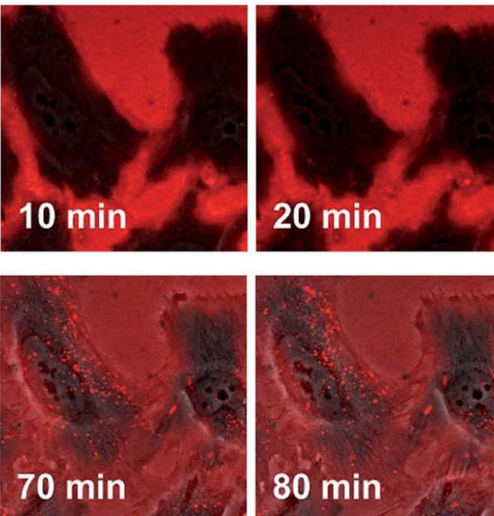
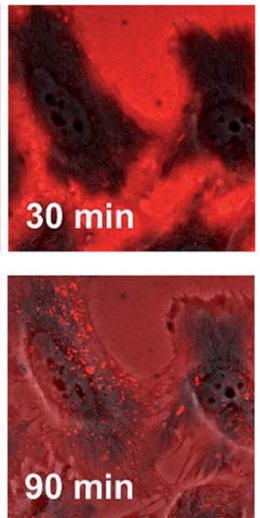
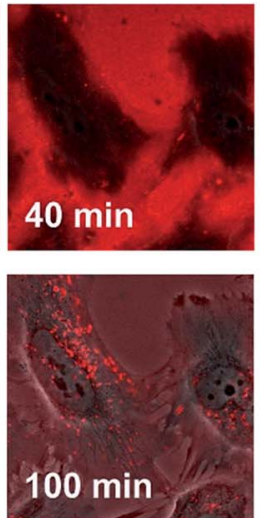
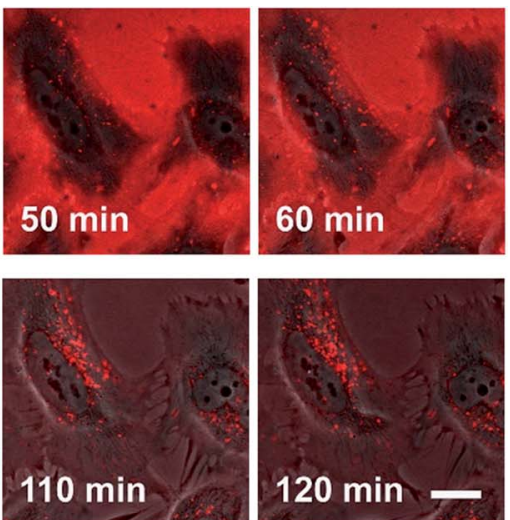

Fig. 10 Confocal microscope images of HeLa cells at $37^{\circ} \mathrm{C}$ with $5 \mathrm{M}(500 \mathrm{nM})$. Merged bright field image with fluorescence image $\left(\lambda_{\text {ex }}=559 \mathrm{~nm}\right.$; $\lambda_{\mathrm{em}}=570-670 \mathrm{~nm}$ ) between $10 \mathrm{~min}$ and $120 \mathrm{~min}$ after staining. Scale bar: $20 \mu \mathrm{m}$.

the cell membrane and, after 50 min, small bright spots in the intracellular region are observed. With further incubation time, additional chromophore enters the cell and the signal-to-noise ratio improves as the residual dye in the medium is consumed.
Furthermore, HeLa cells were stained at $4{ }^{\circ} \mathrm{C}$ or at $37^{\circ} \mathrm{C}$ with the presence of $0.1 \% \mathrm{NaN}_{3}$ (Fig. S12 ); both sets of conditions inhibit endocytosis. Both experiments showed much lower fluorescence intensity in comparison with the control a)
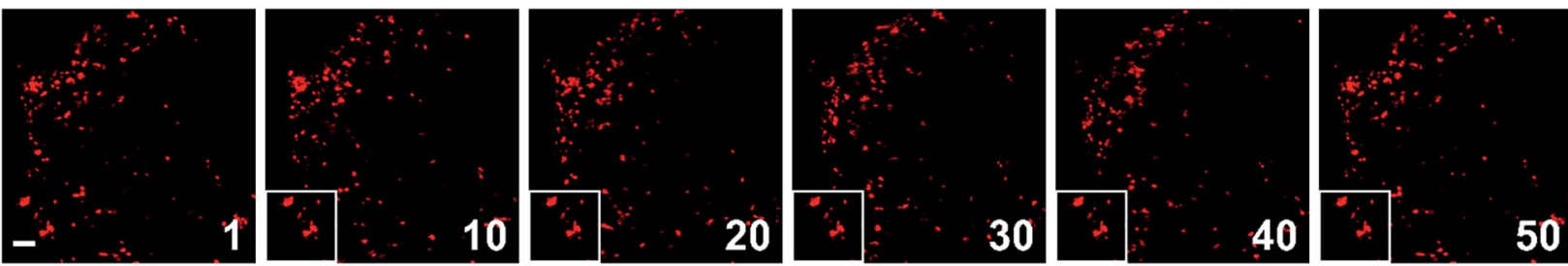

b)
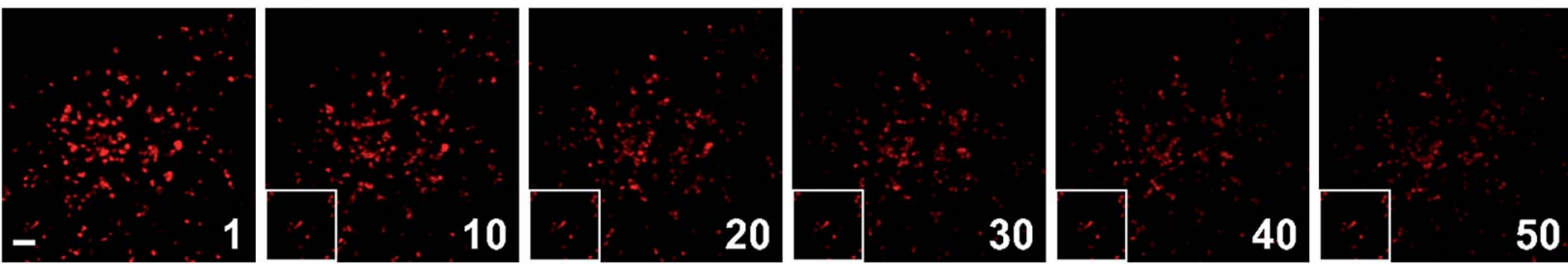

c)
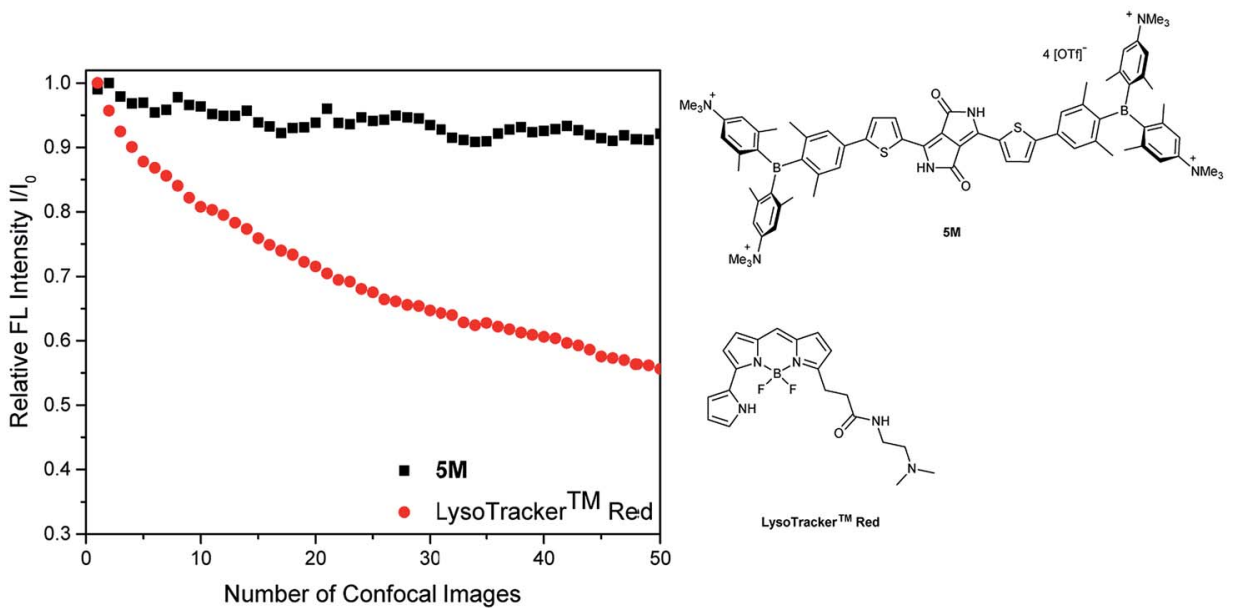

Fig. 11 Comparison of the repeated fluorescence images of HeLa cells stained with (a) $5 \mathrm{M}$ and (b) LysoTrackerTM Red under irradiation with a confocal laser at $561 \mathrm{~nm}$ (WLL, output power 70\%, AOTF 2\%). Each number indicates the number of recorded confocal images. The rectangle (bottom, left in each picture) is the cutout of the image at $n=1$. Scale bar: $2 \mu \mathrm{m}$. (c) Plots of integrated fluorescence intensities (I) relative to the initial value $\left(I_{0}\right)$ as a function of the number of recorded images. 


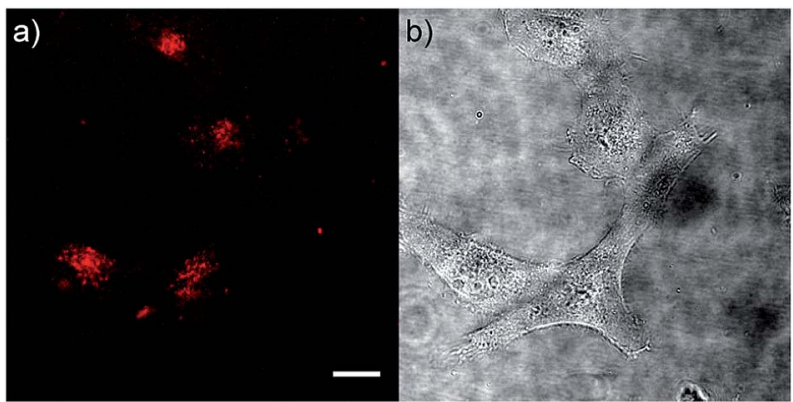

Fig. 12 (a) Two-photon excited fluorescence and (b) bright field images of HeLa cells stained with 5M (500 nM). The TPEF image was recorded under excitation at $720 \mathrm{~nm}$ (AOTF 38\%) using an HyD detector with a bandpass filter 650/50 and an HC Fluotar L $25 \times 0.95 \mathrm{~W}$ VISIR objective. Scale bar: $20 \mu \mathrm{m}$.

experiment, therefore suggesting endocytosis as the mechanism by which $\mathbf{5 M}$ enters cells.

The photostability of our dye $\mathbf{5} \mathbf{M}$ was tested by repetitive imaging of HeLa cells after staining. Over $95 \%$ of the initial fluorescence intensity of $\mathbf{5} \mathbf{M}$ was retained after irradiation with an excitation laser at $561 \mathrm{~nm}$ for 50 images. When using the commercially available LysoTracker ${ }^{\mathrm{TM}}$ Red under the same imaging conditions, the emission intensity decreased by $45 \%$ (Fig. 11). This result revealed the outstanding photostability of $\mathbf{5 M}$, which is highly desired for time-lapse imaging of live cells.

As chromophore $\mathbf{5 M}$ has an outstanding two-photon brightness of $2545 \mathrm{GM}$ (at $740 \mathrm{~nm}$ ) and showed good imaging and cell viability properties, we also tested $\mathbf{5 M}$ as a two-photon excited fluorescence dye to stain HeLa cells. The two-photon imaging experiments were performed at $500 \mathrm{nM}$ concentration. As clearly shown in Fig. 12, dye $\mathbf{5 M}$ stained the cell at the lysosomes and is a very effective two-photon imaging agent.

\section{Conclusion}

We have synthesized a series of quadrupolar A- $\pi-\mathrm{A}$ chromophores with five different $\pi$-bridges, namely biphenyl, pyrene, fluorene, carbazole and dithienyl-diketopyrrolopyrrole all containing triarylborane $\pi$-acceptor groups functionalized to enhance water solubility. While the neutral precursor molecules 1-5 are not water-soluble and are not taken up by the cells, they show interesting photophysical properties. Except for compound $\mathbf{5}$, the neutral dyes are highly solvatochromic as the excited state results from charge transfer from the nitrogens to the boron atoms. As the $N, N$-dimethylaminoxylyl group is present in all of the neutral chromophores, the photophysical properties of those compounds are very similar. After methylation of the four nitrogen atoms, this charge transfer is no longer possible and, therefore, the tetracationic compounds 1M-5M display completely different optical properties. The emission of the different cationic compounds covers nearly the entire visible spectrum depending on the selected $\pi$-bridge. The colour can be tuned from blue to pink over a range of $5300 \mathrm{~cm}^{-1}$, while the emission spectra of compounds themselves are not solvatochromic. The TPA cross-sections correlate with the planarity of the $\pi$-bridge, thus, the more planar the $\pi$-bridge, the higher the two-photon absorption cross-section. The two-photon absorption cross-section also correlates well with the donor ability of the $\pi$-bridge and the length of the conjugated $\pi$-system. Our dithienyldiketopyrrolopyrrole dye $\mathbf{5} \mathbf{M}$ has the highest two-photon cross-section of $4560 \mathrm{GM}$ in MeCN and due to its high fluorescence quantum yield, also exhibits a remarkable two-photon brightness of $2545 \mathrm{GM}$.

We carried out live-cell imaging with all five cationic compounds 1M-5M. All of our cationic dyes were taken up by the HeLa cells and localize at the lysosomes. Furthermore, they do not show any effect on cell viability up to concentrations of $5 \mu \mathrm{M}$, which is much higher than the concentration needed for imaging purposes $(500 \mathrm{nM})$. Further experiments were performed with compound $\mathbf{5 M}$, which shows the most red-shifted absorption and emission, the highest TPA cross-section, no cell toxicity up to 20 times the staining concentration, and a very good co-localization pattern $\left(R_{\mathrm{r}}=0.81\right)$ with the lysosomes. We showed that this dye is taken up by the endocytosis pathway of the HeLa cells, that compound $\mathbf{5 M}$ is far more photostable than the commercially available LysoTracker ${ }^{\mathrm{TM}}$ Red, and that it is an excellent dye for TPEF imaging. In summary, we have designed and synthesized a series of fluorescent three-coordinate boroncontaining quadrupolar dyes for one- and two-photon excited fluorescence imaging of lysosomes. Incorporation of our boron acceptor groups greatly enhances the TPA cross-sections and, via tuning of the $\pi$-bridge, we obtained two-photon absorption cross-sections up to $4560 \mathrm{GM}$ and a two-photon brightness up to $2545 \mathrm{GM}$ in MeCN, which are by far the highest values reported for a lysosomal imaging dye.

\section{Conflicts of interest}

The authors declare no conflict of interest.

\section{Acknowledgements}

We are grateful for generous financial support by the Bavarian State Ministry of Science, Research, and the Arts for the Collaborative Research Network "Solar Technologies go Hybrid", the Deutsche Forschungsgemeinschaft (DFG) (GRK 2112) and the Julius-Maximilians-Universität Würzburg. This work is partly supported by JSPS KAKENHI grant 18H03909, 18H05261, and JP16H06280 (Advanced Bioimaging Support). The authors also gratefully acknowledge the computer and data resources provided by the Leibniz Supercomputing Centre (www.lrz.de). We thank Prof. D. J. Tozer (Durham University) for helpful discussions regarding the TD-DFT calculations.

\section{Notes and references}

$\S$ We are aware that the dipole moment $\mu$ in our charged compounds is origin dependent and not an observable. ${ }^{138,139}$ For simplification, we use the term dipole moment to describe the electron density distribution in our charged compounds. Thus, the terms dipole and quadrupole are used accordingly. 
1 C. D. Entwistle and T. B. Marder, Angew. Chem., Int. Ed., 2002, 41, 2927-2931.

2 C. D. Entwistle and T. B. Marder, Chem. Mater., 2004, 16, 4574-4585.

3 S. Yamaguchi and A. Wakamiya, Pure Appl. Chem., 2006, 78, 1413-1424.

4 F. Jäkle, Coord. Chem. Rev., 2006, 250, 1107-1121.

5 M. Elbing and G. C. Bazan, Angew. Chem., Int. Ed., 2008, 47, 834-838.

6 Z. M. Hudson and S. Wang, Acc. Chem. Res., 2009, 42, 15841596.

7 Y. Ren and F. Jäkle, Dalton Trans., 2016, 45, 13996-14007.

8 L. Ji, S. Griesbeck and T. B. Marder, Chem. Sci., 2017, 8, 846863.

9 E. von Grotthuss, A. John, T. Kaese and M. Wagner, Asian J. Org. Chem., 2018, 7, 37-53.

10 X. Yin, J. Chen, R. A. Lalancette, T. B. Marder and F. Jäkle, Angew. Chem., Int. Ed., 2014, 53, 9761-9765.

11 Z. Zhang, R. M. Edkins, M. Haehnel, M. Wehner, A. Eichhorn, L. Mailänder, M. Meier, J. Brand, F. Brede, K. Müller-Buschbaum, H. Braunschweig and T. B. Marder, Chem. Sci., 2015, 6, 5922-5927.

12 Z. Zhou, A. Wakamiya, T. Kushida and S. Yamaguchi, J. Am. Chem. Soc., 2012, 134, 4529-4532.

13 T. W. Hudnall, C.-W. Chiu and F. P. Gabbaï, Acc. Chem. Res., 2009, 42, 388-397.

14 C. R. Wade, A. E. J. Broomsgrove, S. Aldridge and F. P. Gabbaï, Chem. Rev., 2010, 110, 3958-3984.

15 F. Jäkle, Chem. Rev., 2010, 110, 3985-4022.

16 Y. Chen, D. Cao, S. Wang, C. Zhang and Z. Liu, J. Mol. Struct., 2010, 969, 182-186.

17 J. Ohshita, Y. Tominaga, D. Tanaka, Y. Ooyama, T. Mizumo, N. Kobayashi and H. Higashimura, Dalton Trans., 2013, 42, 3646-3652.

18 G. Turkoglu, M. E. Cinar and T. Ozturk, Eur. J. Org. Chem., 2017, 2017, 4552-4561.

19 D. Mutaguchi, K. Okumoto, Y. Ohsedo, K. Moriwaki and Y. Shirota, Org. Electron., 2003, 4, 49-59.

20 G. Zhou, C.-L. Ho, W.-Y. Wong, Q. Wang, D. Ma, L. Wang, Z. Lin, T. B. Marder and A. Beeby, Adv. Funct. Mater., 2008, 18, 499-511.

21 Z. M. Hudson, C. Sun, M. G. Helander, Y.-L. Chang, Z.-H. Lu and S. Wang, J. Am. Chem. Soc., 2012, 134, 13930-13933.

22 M. Numata, T. Yasuda and C. Adachi, Chem. Commun., 2015, 51, 9443-9446.

23 K. Suzuki, S. Kubo, K. Shizu, T. Fukushima, A. Wakamiya, Y. Murata, C. Adachi and H. Kaji, Angew. Chem., Int. Ed., 2015, 54, 15231-15235.

24 I. S. Park, M. Numata, C. Adachi and T. Yasuda, Bull. Chem. Soc. Jpn., 2016, 89, 375-377.

25 Y. Liu, G. Xie, K. Wu, Z. Luo, T. Zhou, X. Zeng, J. Yu, S. Gong and C. Yang, J. Mater. Chem. C, 2016, 4, 4402-4407.

26 T. Hatakeyama, K. Shiren, K. Nakajima, S. Nomura, S. Nakatsuka, K. Kinoshita, J. Ni, Y. Ono and T. Ikuta, Adv. Mater., 2016, 28, 2777-2781.

27 Y. H. Lee, S. Park, J. Oh, J. W. Shin, J. Jung, S. Yoo and M. H. Lee, ACS Appl. Mater. Interfaces, 2017, 9, 24035-24042.
28 J. E. Leffler, G. B. Watts, T. Tanigaki, E. Dolan and D. S. Miller, J. Am. Chem. Soc., 1970, 92, 6825-6830.

29 T. Noda and Y. Shirota, J. Am. Chem. Soc., 1998, 120, 97149715.

30 M. Kinoshita and Y. Shirota, Chem. Lett., 2001, 30, 614-615.

31 A. Shuto, T. Kushida, T. Fukushima, H. Kaji and S. Yamaguchi, Org. Lett., 2013, 15, 6234-6237.

32 G. Turkoglu, M. E. Cinar and T. Ozturk, Molecules, 2017, 22, 1522.

33 W. Kaim and A. Schulz, Angew. Chem., Int. Ed., 1984, 23, 615-616.

34 W. Kaim, N. S. Hosmane, S. Záliš, J. A. Maguire and W. N. Lipscomb, Angew. Chem., Int. Ed., 2009, 48, 50825091.

35 L. Ji, R. M. Edkins, A. Lorbach, I. Krummenacher, C. Brückner, A. Eichhorn, H. Braunschweig, B. Engels, P. J. Low and T. B. Marder, J. Am. Chem. Soc., 2015, 137, 6750-6753.

36 J. Merz, J. Fink, A. Friedrich, I. Krummenacher, H. H. Al Mamari, S. Lorenzen, M. Haehnel, A. Eichhorn, M. Moos, M. Holzapfel, H. Braunschweig, C. Lambert, A. Steffen, L. Ji and T. B. Marder, Chem.-Eur. J., 2017, 23, 13164-13180.

37 L. Ji, I. Krummenacher, A. Friedrich, A. Lorbach, M. Haehnel, K. Edkins, H. Braunschweig and T. B. Marder, J. Org. Chem., 2018, 83, 3599-3606.

38 J. C. Doty, B. Babb, P. J. Grisdale, M. Glogowski and J. L. R. Williams, J. Organomet. Chem., 1972, 38, 229-236.

39 Z. Yuan, C. D. Entwistle, J. C. Collings, D. Albesa-Jové, A. S. Batsanov, J. A. K. Howard, N. J. Taylor, H. M. Kaiser, D. E. Kaufmann, S.-Y. Poon, W.-Y. Wong, C. Jardin, S. Fathallah, A. Boucekkine, J.-F. Halet and T. B. Marder, Chem.-Eur. J., 2006, 12, 2758-2771.

40 J. C. Collings, S.-Y. Poon, C. Le Droumaguet, M. Charlot, C. Katan, L.-O. Pålsson, A. Beeby, J. A. Mosely, H. M. Kaiser, D. Kaufmann, W.-Y. Wong, M. BlanchardDesce and T. B. Marder, Chem.-Eur. J., 2009, 15, 198-208.

41 L. Weber, D. Eickhoff, T. B. Marder, M. A. Fox, P. J. Low, A. D. Dwyer, D. J. Tozer, S. Schwedler, A. Brockhinke, H.-G. Stammler and B. Neumann, Chem.-Eur. J., 2012, 18, 1369-1382.

42 Z. Zhang, R. M. Edkins, J. Nitsch, K. Fucke, A. Eichhorn, A. Steffen, Y. Wang and T. B. Marder, Chem.-Eur. J., 2015, 21, 177-190.

43 Z. Zhang, R. M. Edkins, J. Nitsch, K. Fucke, A. Steffen, L. E. Longobardi, D. W. Stephan, C. Lambert and T. B. Marder, Chem. Sci., 2015, 6, 308-321.

44 S.-Y. Li, Z.-B. Sun and C.-H. Zhao, Inorg. Chem., 2017, 56, 8705-8717.

45 M. Ito, E. Ito, M. Hirai and S. Yamaguchi, J. Org. Chem., 2018, 83, 8449-8456.

46 M. Meier, L. Ji, J. Nitsch, I. Krummenacher, A. Deißenberger, D. Auerhammer, M. Schäfer, T. B. Marder and H. Braunschweig, Chem.-Eur. J., 2019, 25, 4707-4712.

47 H. M. Kim and B. R. Cho, Chem. Rev., 2015, 115, 50145055. 
48 C. C. Jiménez, A. Enríquez-Cabrera, O. González-Antonio, J. Ordóñez-Hernández, P. G. Lacroix, P. Labra-Vázquez, N. Farfán and R. Santillan, Inorganics, 2018, 6, 131.

49 F. Terenziani, C. Katan, E. Badaeva, S. Tretiak and M. Blanchard-Desce, Adv. Mater., 2008, 20, 4641-4678.

50 G. S. He, L.-S. Tan, Q. Zheng and P. N. Prasad, Chem. Rev., 2008, 108, 1245-1330.

51 M. Rumi, S. Barlow, J. Wang, J. W. Perry and S. R. Marder, in Photoresponsive Polymers I, ed. S. R. Marder and K.-S. Lee, Springer, Berlin, 2008, vol. 213, pp. 1-95.

52 M. Pawlicki, H. A. Collins, R. G. Denning and H. L. Anderson, Angew. Chem., Int. Ed., 2009, 48, 3244-3266.

53 H. M. Kim and B. R. Cho, Chem. Commun., 2009, 153-164. 54 B. H. Cumpston, S. P. Ananthavel, S. Barlow, D. L. Dyer, J. E. Ehrlich, L. L. Erskine, A. A. Heikal, S. M. Kuebler, I. Y. S. Lee, D. McCord-Maughon, J. Qin, H. Röckel, M. Rumi, X.-L. Wu, S. R. Marder and J. W. Perry, Nature, 1999, 398, 51.

55 S. Kawata, H.-B. Sun, T. Tanaka and K. Takada, Nature, 2001, 412, 697.

56 W. Zhou, S. M. Kuebler, K. L. Braun, T. Yu, J. K. Cammack, C. K. Ober, J. W. Perry and S. R. Marder, Science, 2002, 296, 1106-1109.

57 S. Juodkazis, V. Mizeikis and H. Misawa, J. Appl. Phys., 2009, 106, 051101.

58 D. A. Parthenopoulos and P. M. Rentzepis, Science, 1989, 245, 843-845.

59 S. Kawata and Y. Kawata, Chem. Rev., 2000, 100, 1777-1788.

60 W. Dallari, M. Scotto, M. Allione, E. Samoylova, F. Pignatelli, R. Cingolani, A. Athanassiou and A. Diaspro, Microelectron. Eng., 2011, 88, 3466-3469.

61 G. S. He, J. D. Bhawalkar, C. F. Zhao and P. N. Prasad, Appl. Phys. Lett., 1995, 67, 2433-2435.

62 J. E. Ehrlich, X. L. Wu, I. Y. S. Lee, Z. Y. Hu, H. Röckel, S. R. Marder and J. W. Perry, Opt. Lett., 1997, 22, 1843-1845.

63 C. W. Spangler, J. Mater. Chem., 1999, 9, 2013-2020.

64 G. S. He, R. Signorini and P. N. Prasad, Appl. Opt., 1998, 37, 5720-5726.

65 A. Abbotto, L. Beverina, R. Bozio, S. Bradamante, C. Ferrante, G. A. Pagani and R. Signorini, Adv. Mater., 2000, 12, 1963-1967.

66 W. G. Fisher, W. P. Partridge, C. Dees and E. A. Wachter, Photochem. Photobiol., 1997, 66, 141-155.

67 Y. Shen, A. J. Shuhendler, D. Ye, J.-J. Xu and H.-Y. Chen, Chem. Soc. Rev., 2016, 45, 6725-6741.

68 W. Denk, J. Strickler and W. Webb, Science, 1990, 248, 7376.

69 P. Ning, W. Wang, M. Chen, Y. Feng and X. Meng, Chin. Chem. Lett., 2017, 28, 1943-1951.

70 Q. Zhang, X. Tian, H. Zhou, J. Wu and Y. Tian, Materials, 2017, 10, 223.

71 S. Yao and K. D. Belfield, Eur. J. Org. Chem., 2012, 2012, 3199-3217.

72 D. Kim, H. G. Ryu and K. H. Ahn, Org. Biomol. Chem., 2014, 12, 4550-4566.

73 J. A. Mindell, Annu. Rev. Physiol., 2012, 74, 69-86.
74 C. Settembre, A. Fraldi, D. L. Medina and A. Ballabio, Nat. Rev. Mol. Cell Biol., 2013, 14, 283.

75 F. M. Platt, B. Boland and A. C. van der Spoel, J. Cell Biol., 2012, 199, 723-734.

76 H. M. Kim, M. J. An, J. H. Hong, B. H. Jeong, O. Kwon, J.-Y. Hyon, S.-C. Hong, K. J. Lee and B. R. Cho, Angew. Chem., Int. Ed., 2008, 47, 2231-2234.

77 J. H. Han, S. K. Park, C. S. Lim, M. K. Park, H. J. Kim, H. M. Kim and B. R. Cho, Chem.-Eur. J., 2012, 18, 1524615249.

78 H. J. Kim, C. H. Heo and H. M. Kim, J. Am. Chem. Soc., 2013, 135, 17969-17977.

79 L. Yuan, L. Wang, B. K. Agrawalla, S.-J. Park, H. Zhu, B. Sivaraman, J. Peng, Q.-H. Xu and Y.-T. Chang, J. Am. Chem. Soc., 2015, 137, 5930-5938.

80 H. Yu, Y. Xiao and L. Jin, J. Am. Chem. Soc., 2012, 134, 17486-17489.

81 H.-J. Lee, C.-W. Cho, H. Seo, S. Singha, Y. W. Jun, K.-H. Lee, Y. Jung, K.-T. Kim, S. Park, S. C. Bae and K. H. Ahn, Chem. Commun., 2016, 52, 124-127.

82 B. Zhu, P. Li, W. Shu, X. Wang, C. Liu, Y. Wang, Z. Wang, Y. Wang and B. Tang, Anal. Chem., 2016, 88, 12532-12538. 83 J. Fan, Z. Han, Y. Kang and X. Peng, Sci. Rep., 2016, 6, 19562. 84 L. Zhou, Y. Liu, S. Hu, H. Wang, H. Sun and X. Zhang, Tetrahedron, 2016, 72, 4637-4642.

85 H. Chen, Y. Tang, H. Shang, X. Kong, R. Guo and W. Lin, J. Mater. Chem. B, 2017, 5, 2436-2444.

86 W. Feng, Z. Mao, L. Liu and Z. Liu, Talanta, 2017, 167, 134142.

87 W. Luo, H. Jiang, X. Tang and W. Liu, J. Mater. Chem. B, 2017, 5, 4768-4773.

88 J. Huang, N. Li, Q. Wang, Y. Gu and P. Wang, Sens. Actuators, B, 2017, 246, 833-839.

89 Y. Liu, F. Meng, L. He, K. Liu and W. Lin, Chem. Commun., 2016, 52, 7016-7019.

90 J. Jiang, X. Tian, C. Xu, S. Wang, Y. Feng, M. Chen, H. Yu, M. Zhu and X. Meng, Chem. Commun., 2017, 53, 3645-3648.

91 J. H. Son, C. S. Lim, J. H. Han, I. A. Danish, H. M. Kim and B. R. Cho, J. Org. Chem., 2011, 76, 8113-8116.

92 M. Tian, Y. Sun, L. Guo, R. Zhang, G. Zhang, R. Feng, X. Li, H. Zhang, L. He, X. Yu and X. He, Sens. Actuators, B, 2017, 243, 955-962.

93 X. Wang, D. M. Nguyen, C. O. Yanez, L. Rodriguez, H.-Y. Ahn, M. V. Bondar and K. D. Belfield, J. Am. Chem. Soc., 2010, 132, 12237-12239.

94 S. Yao, H.-Y. Ahn, X. Wang, J. Fu, E. W. Van Stryland, D. J. Hagan and K. D. Belfield, J. Org. Chem., 2010, 75, 3965-3974.

95 C. D. Andrade, C. O. Yanez, M. A. Qaddoura, X. Wang, C. L. Arnett, S. A. Coombs, J. Yu, R. Bassiouni, M. V. Bondar and K. D. Belfield, J. Fluoresc., 2011, 21, 1223-1230.

96 C. S. Lim, S. T. Hong, S. S. Ryu, D. E. Kang and B. R. Cho, Chem.-Asian J., 2015, 10, 2240-2249.

97 A. L. Capodilupo, V. Vergaro, E. Fabiano, M. De Giorgi, F. Baldassarre, A. Cardone, A. Maggiore, V. Maiorano, 
D. Sanvitto, G. Gigli and G. Ciccarella, J. Mater. Chem. B, 2015, 3, 3315-3323.

98 S. Chen, M. Zhao, J. Su, Q. Zhang, X. Tian, S. Li, H. Zhou, J. Wu and Y. Tian, Dyes Pigm., 2017, 136, 807-816.

99 Z. Yuan, N. J. Taylor, R. Ramachandran and T. B. Marder, Appl. Organomet. Chem., 1996, 10, 305-316.

100 M. Charlot, L. Porrès, C. D. Entwistle, A. Beeby, T. B. Marder and M. Blanchard-Desce, Phys. Chem. Chem. Phys., 2005, 7, 600-606.

101 C. D. Entwistle, J. C. Collings, A. Steffen, L.-O. Pålsson, A. Beeby, D. Albesa-Jové, J. M. Burke, A. S. Batsanov, J. A. K. Howard, J. A. Mosely, S.-Y. Poon, W.-Y. Wong, F. Ibersiene, S. Fathallah, A. Boucekkine, J.-F. Halet and T. B. Marder, J. Mater. Chem., 2009, 19, 7532-7544.

102 L. Ji, R. M. Edkins, L. J. Sewell, A. Beeby, A. S. Batsanov, K. Fucke, M. Drafz, J. A. K. Howard, O. Moutounet, F. Ibersiene, A. Boucekkine, E. Furet, Z. Liu, J.-F. Halet, C. Katan and T. B. Marder, Chem.-Eur. J., 2014, 20, 13618-13635.

103 C.-W. Chiu, Y. Kim and F. P. Gabbaï, J. Am. Chem. Soc., 2009, 131, 60-61.

104 Y. Kim and F. P. Gabbaï, J. Am. Chem. Soc., 2009, 131, 33633369.

105 T. Agou, M. Sekine, J. Kobayashi and T. Kawashima, Chem.Eur. J., 2009, 15, 5056-5062.

106 K. C. Song, K. M. Lee, N. V. Nghia, W. Y. Sung, Y. Do and M. H. Lee, Organometallics, 2013, 32, 817-823.

107 X. Li, X. Guo, L. Cao, Z. Xun, S. Wang, S. Li, Y. Li and G. Yang, Angew. Chem., Int. Ed., 2014, 53, 7809-7813.

108 J. Liu, X. Guo, R. Hu, X. Liu, S. Wang, S. Li, Y. Li and G. Yang, Anal. Chem., 2016, 88, 1052-1057.

109 J. Liu, S. Zhang, C. Zhang, J. Dong, C. Shen, J. Zhu, H. Xu, M. Fu, G. Yang and X. Zhang, Chem. Commun., 2017, 53, 11476-11479.

110 J. Liu, S. Li, S. Zhang, C. Shen, J. Zhu, G. Yang and X. Zhang, Sens. Actuators, B, 2018, 261, 531-536.

111 J. Liu, X. Guo, R. Hu, J. Xu, S. Wang, S. Li, Y. Li and G. Yang, Anal. Chem., 2015, 87, 3694-3698.

112 X. Guo, X. Zhang, S. Wang, S. Li, R. Hu, Y. Li and G. Yang, Anal. Chim. Acta, 2015, 869, 81-88.

113 B. Chen, G. Feng, B. He, C. Goh, S. Xu, G. Ramos-Ortiz, L. Aparicio-Ixta, J. Zhou, L. Ng, Z. Zhao, B. Liu and B. Z. Tang, Small, 2016, 12, 782-792.

114 J. Liu, C. Zhang, J. Dong, J. Zhu, C. Shen, G. Yang and X. Zhang, RSC Adv., 2017, 7, 14511-14515.

115 J. Liu, C. Zhang, J. Dong, J. Zhu, C. Shen, G. Yang and X. Zhang, New J. Chem., 2017, 41, 4733-4737.

116 S. Pagidi, N. K. Kalluvettukuzhy and P. Thilagar, Langmuir, 2018, 34, 8170-8177.

117 S. Griesbeck, Z. Zhang, M. Gutmann, T. Lühmann, R. M. Edkins, G. Clermont, A. N. Lazar, M. Haehnel,
K. Edkins, A. Eichhorn, M. Blanchard-Desce, L. Meinel and T. B. Marder, Chem.-Eur. J., 2016, 22, 14701-14706.

118 M. Grzybowski and D. T. Gryko, Adv. Opt. Mater., 2015, 3, 280-320.

119 M. Kaur and D. H. Choi, Chem. Soc. Rev., 2015, 44, 58-77.

120 A. Nowak-Król, M. Grzybowski, J. Romiszewski, M. Drobizhev, G. Wicks, M. Chotkowski, A. Rebane, E. Górecka and D. T. Gryko, Chem. Commun., 2013, 49, 8368-8370.

121 J. Schmitt, V. Heitz, A. Sour, F. Bolze, H. Ftouni, J.-F. Nicoud, L. Flamigni and B. Ventura, Angew. Chem., Int. Ed., 2015, 54, 169-173.

122 A. G. Crawford, A. D. Dwyer, Z. Liu, A. Steffen, A. Beeby, L.-O. Pålsson, D. J. Tozer and T. B. Marder, J. Am. Chem. Soc., 2011, 133, 13349-13362.

123 L. Ji, A. Lorbach, R. M. Edkins and T. B. Marder, J. Org. Chem., 2015, 80, 5658-5665.

124 R. Englman and J. Jortner, Mol. Phys., 1970, 18, 145-164.

125 S. J. Strickler and R. A. Berg, J. Chem. Phys., 1962, 37, 814822.

126 R. Stahl, C. Lambert, C. Kaiser, R. Wortmann and R. Jakober, Chem.-Eur. J., 2006, 12, 2358-2370.

127 E. Sakuda, Y. Ando, A. Ito and N. Kitamura, J. Phys. Chem. A, 2010, 114, 9144-9150.

128 A. Ito, K. Kawanishi, E. Sakuda and N. Kitamura, Chem.Eur. J., 2014, 20, 3940-3953.

129 S. Amthor, C. Lambert, S. Dümmler, I. Fischer and J. Schelter, J. Phys. Chem. A, 2006, 110, 5204-5214.

130 H.-J. Jo, C.-B. Kim, T.-Y. Ryoo, B.-K. Ahn and K.-Y. Park, Bull. Korean Chem. Soc., 2010, 31, 3749-3754.

131 N. Agarwal, P. K. Nayak, F. Ali, M. P. Patankar, K. L. Narasimhan and N. Periasamy, Synth. Met., 2011, 161, 466-473.

132 B. Kobin, S. Behren, B. Braun-Cula and S. Hecht, J. Phys. Chem. A, 2016, 120, 5474-5480.

133 J. Cortes, H. Heitele and J. Jortner, J. Phys. Chem., 1994, 98, 2527-2536.

134 M. Li, J. Fan, H. Li, J. Du, S. Long and X. Peng, Biomaterials, 2018, 164, 98-105.

135 N. Jiang, J. Fan, F. Xu, X. Peng, H. Mu, J. Wang and X. Xiong, Angew. Chem., Int. Ed., 2015, 54, 2510-2514.

136 D. Scherer, R. Dörfler, A. Feldner, T. Vogtmann, M. Schwoerer, U. Lawrentz, W. Grahn and C. Lambert, Chem. Phys., 2002, 279, 179-207.

137 B. Strehmel, S. Amthor, J. Schelter and C. Lambert, ChemPhysChem, 2005, 6, 893-896.

138 A. D. Buckingham, Q. Rev., Chem. Soc., 1959, 13, 183-214.

139 D. J. Griffiths, in Introduction to Electrodynamics, Prentice Hall, Inc., New Jersey, 3rd edn, 1999, pp. 146-159. 